\title{
Structure and dynamics of decadal anomalies in the wintertime midlatitude North Pacific ocean-atmosphere system
}

\author{
Jiabei Fang ${ }^{1}$ Xiu-Qun Yang ${ }^{1}$
}

Received: 8 January 2015 / Accepted: 9 December 2015 / Published online: 21 December 2015

(c) The Author(s) 2015. This article is published with open access at Springerlink.com

\begin{abstract}
The structure and dynamics of decadal anomalies in the wintertime midlatitude North Pacific oceanatmosphere system are examined in this study, using the NCEP/NCAR atmospheric reanalysis, HadISST SST and Simple Ocean Data Assimilation data for 1960-2010. The midlatitude decadal anomalies associated with the Pacific Decadal Oscillation are identified, being characterized by an equivalent barotropic atmospheric low (high) pressure over a cold (warm) oceanic surface. Such a unique configuration of decadal anomalies can be maintained by an unstable ocean-atmosphere interaction mechanism in the midlatitudes, which is hypothesized as follows. Associated with a warm PDO phase, an initial midlatitude surface westerly anomaly accompanied with intensified Aleutian low tends to force a negative SST anomaly by increasing upward surface heat fluxes and driving southward Ekman current anomaly. The SST cooling tends to increase the meridional SST gradient, thus enhancing the subtropical oceanic front. As an adjustment of the atmospheric boundary layer to the enhanced oceanic front, the low-level atmospheric meridional temperature gradient and thus the low-level atmospheric baroclinicity tend to be strengthened, inducing more active transient eddy activities that increase transient eddy vorticity forcing. The vorticity forcing that dominates the total atmospheric forcing tends to produce an equivalent barotropic atmospheric low pressure north of the initial westerly anomaly, intensifying the initial anomalies of the midlatitude surface westerly and Aleutian low. Therefore,
\end{abstract}

Xiu-Qun Yang

xqyang@nju.edu.cn

1 Institute for Climate and Global Change Research, Jiangsu Collaborative Innovation Center for Climate Change, School of Atmospheric Sciences, Nanjing University, Nanjing 210023, China it is suggested that the midlatitude ocean-atmosphere interaction can provide a positive feedback mechanism for the development of initial anomaly, in which the oceanic front and the atmospheric transient eddy are the indispensable ingredients. Such a positive ocean-atmosphere feedback mechanism is fundamentally responsible for the observed decadal anomalies in the midlatitude North Pacific ocean-atmosphere system.

Keywords Decadal anomalies - Ocean-atmosphere interaction · Oceanic front $\cdot$ Transient eddy $\cdot$ Midlatitude North Pacific

\section{Introduction}

Since the mid-1990s, a variety of observational studies have discovered the existence of the midlatitude climate variabilities on decadal to inter-decadal time scales in both the atmosphere and the ocean, such as the Pacific Decadal Oscillation (PDO) over North Pacific and the North Atlantic Oscillation (NAO) over North Atlantic (Trenberth 1990; Graham et al. 1994; Kushnir 1994; Minobe 1997; Mantua et al. 1997; Enfield and Mestas-Nunez 1999; Zhu and Yang 2003a; Deser et al. 2004; Fang et al. 2006). The spatiotemporal patterns of the decadal variabilities in the atmosphere and in the ocean are well correlated during winter. The atmospheric circulation anomalies associated with large-scale SST anomalies on decadal timescale exhibit an equivalent barotropic structure in the vertical direction, with lows (highs) above cold (warm) water (Kushnir et al. 2002; Namias and Cayan 1981; Cayan 1992; Deser and Blackman 1993). Such decadal variabilities have important impact on the large scale climate anomalies especially those in East Asia (Zhu and Yang 2003b; Yang et al. 2005; 
Xu et al. 2005; Zhu et al. 2008a, b; Yang and Zhu 2008). Thus the mechanism of decadal climate variabilities has become the focus of climate dynamics research (Liu 2012).

Because the typical timescale of midlatitude upperocean is up to 10 years, the midlatitude ocean-atmosphere interaction is generally considered to be a potential source of decadal-to-interdecadal climate variability (Latif and Barnett 1996; Miller and Schneider 2000; Zhong et al. 2008; Zhu et al. 2008a, b; Fang and Yang 2011). During the past decade, a number of observations, theoretical analyses and GCM simulations have provided evidence for the feedback of extratropical sea surface temperature (SST) on large-scale atmospheric circulation by not only passive response, but also active coupling (Saravanan and McWilliams 1997, 1998; Neelin and Weng 1999; Latif and Barnett 1996; Liu and Wu 2004; Zhong et al. 2008; Zhu et al. 2008b; Fang and Yang 2011). The atmospheric impact on the midlatitude ocean has been well examined. It is widely agreed that the midlatitude SST anomalies are mainly caused by the atmosphere through air-sea heat fluxes and upper-ocean current response. The decadal timescale of the climate variability is determined by the slow upper ocean adjustment processes as response to the atmospheric forcing. These adjustment processes involve the oceanic gyre (Latif and Barnett 1994), the subduction (Gu and Philander 1997) and the oceanic Rossby wave propagation (Qiu et al. 2007). However, how the midlatitude ocean influences the atmosphere is still an unsolved issue. Atmospheric responses to heating or prescribed SST anomalies in different simple or complex models are not consistent. Some of those responses are barotropic, with atmospheric high pressure over warm oceanic surface, as in observation (Palmer and Sun 1985; Latif and Barnett 1994, 1996; Peng et al. 1995, 1997), or with atmospheric low pressure over warm oceanic surface (Picther et al. 1988; Kushnir and Lau 1992; Peng and Whitaker 1999), and others are baroclinic (Hoskins and Karoly 1981; Kushnir and Held 1996). In terms of Frankignoul (1985), the differences in those model simulations can be attributed to the different distributions of the atmospheric heating and cooling anomalies induced by the midlatitude SST anomalies. Peng et al. (1997) and Peng and Whitaker (1999) also indicated that the response of atmospheric models to the midlatitude SST anomalies is strongly dependent on the accurate simulation of climatological mean state and transient eddy feedback in the models. Therefore, understanding the mechanism of the midlatitude ocean's impact on the atmosphere, especially the role of transient eddy feedback, is still an open question.

The midlatitude atmosphere has strong baroclinicity and strong internal variability, in which transient eddies accompanied with jet stream and storm track develop vigorously (Ren et al. 2010; Chu et al. 2013; Liu et al. 2014). The synoptic transient eddies can transport heat and momentum flux in the atmosphere, and thus can redistribute the heat and momentum in space. Moreover, the region of storm track and strong transient eddy activities is corresponding to the oceanic front zone in the midlatitudes. In recent years, observational studies with high-resolution satellite data (Nakamura et al. 2004; Small et al. 2008) and numerical studies with high-resolution GCM (Minobe et al. 2008; Taguchi et al. 2009; Sampe et al. 2010; Czaja and Blunt 2011; Feliks et al. 2004, 2007, 2011) have shown that the SST anomalies associated with midlatitude oceanic front zones can influence the time-mean atmospheric circulation beyond planetary boundary layer. Therefore, the transient eddies not only play an important role in driving and maintaining midlatitude atmospheric circulation (Ren et al. 2011; Xiang and Yang 2012; Zhang et al. 2012; Nie et al. 2013, 2014), but also may act as a main dynamical process through which the midlatitude ocean thermal condition can affect the atmosphere (Ren et al. 2007).

This study aims at investigating the role of midlatitude ocean-atmosphere interaction in the wintertime decadal climate variability over the North Pacific. The focus will be on the dynamical processes of atmospheric response to the midlatitude SST anomalies associated with the oceanic front variations through thermal and dynamical forcing sources that include the direct diabatic heating and indirect transient eddy forcing. The relative contributions of different kinds of atmospheric forcing to the formation of atmospheric circulation response structure are also discussed through quantitative analyses. A hypothesis for unstable ocean-atmosphere interaction in the midlatitudes is proposed. In this hypothesis, the role of the atmospheric transient eddy forcing induced by the oceanic front in how the midlatitude SST anomalies affect the atmospheric anomalies is emphasized. The paper is organized as follows. The data used is described in Sect. 2. In Sect. 3, typical structure features of the decadal anomalies in the wintertime midlatitude North Pacific and their configuration relationship are identified. The processes of atmospheric forcing on the ocean and those of atmospheric response to the ocean are examined in Sects. 4 and 5, respectively. In Sect. 6, a possible unstable ocean-atmosphere interaction mechanism is proposed to explain observed decadal anomalies in the midlatitude North Pacific. The final section is devoted to the conclusions and discussion.

\section{Data}

In the present study, the wintertime (DJF) refers to the months of December, January and February. Monthlymean atmospheric variables, including geopotential height, wind velocity and air temperature at 12 standard pressure levels from 1000 to $100 \mathrm{hPa}$, as well as sea level pressure 


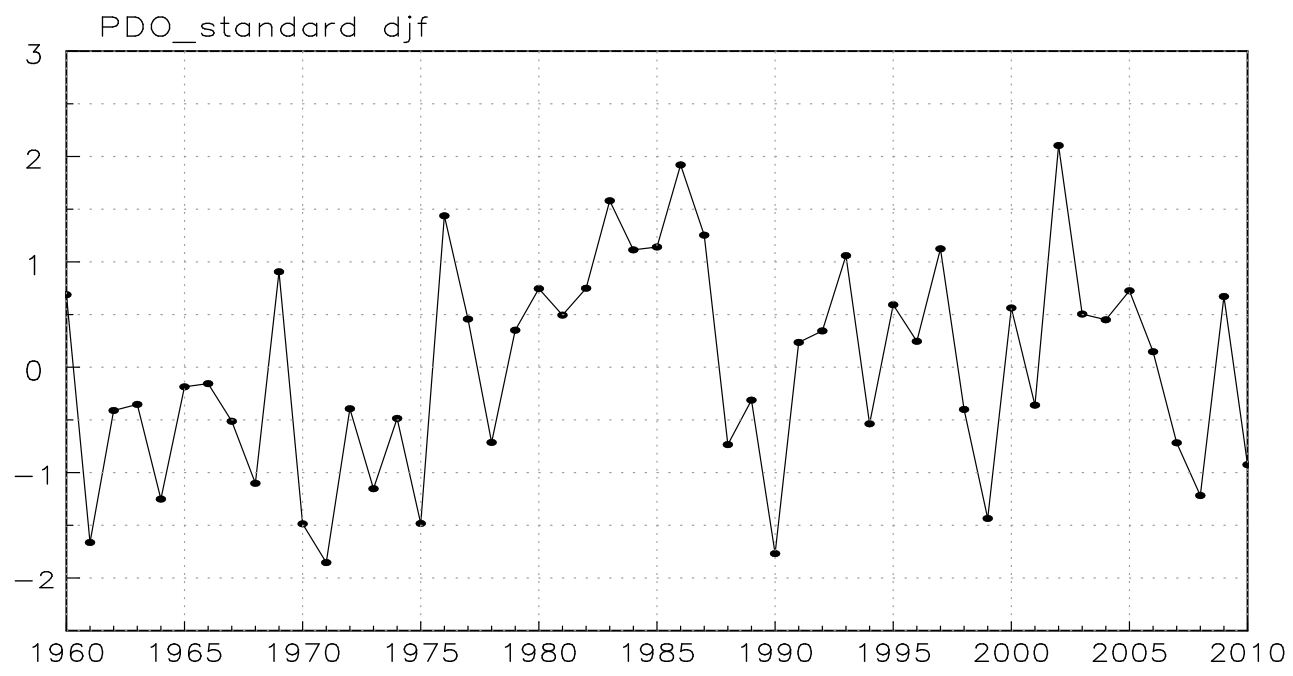

Fig. 1 Time series of the wintertime (DJF) standardized PDO index for 1960-2010. Downloaded from website http://jisao.washington.edu/pdo/ PDO.latest

(SLP) and surface heat flux, are taken from NCEP/NCAR monthly reanalysis data for the period 1960 to 2010 . The horizontal resolution of reanalysis data is $2.5^{\circ} \times 2.5^{\circ}$. Monthly SST and upper-layer $(0-100 \mathrm{~m}$ averaged) oceanic current data are taken from the Hadley Center Sea Ice and SST dataset (HadISST) version 1.1 on $1^{\circ} \times 1^{\circ}$ grid, provided by the Met Office and Simple Ocean Data Assimilation (SODA) version 2.2.4, respectively. In addition, 6-hourly NCEP/NCAR reanalysis data are also used to calculate seasonal-mean transient eddy thermal and dynamical forcing based on their definitions in Sect. 5. The seasonal-mean diabatic heating is diagnosed as a residual in the thermodynamic equation. The PDO index is downloaded from website http://jisao.washington.edu/pdo/PDO. latest. The decadal anomaly of each variable is expressed by its regression on the PDO index. Furthermore, the atmospheric baroclinicity in this study is represented by the Eady growth rate that is calculated according to the relation $\sigma_{B I}=0.31 f|\partial \vec{V} / \partial z| / N$.

\section{Structure of the decadal anomalies over the midlatitude North Pacific}

The Pacific Decadal Oscillation (PDO) is the dominant climate variability in the North Pacific on decadal-to-interdecadal timescale, and it is defined as the leading EOF mode of the North Pacific monthly SST anomalies north of $20^{\circ} \mathrm{N}$. Figure 1 shows the time series of standardized wintertime (DJF) PDO index for 1960-2010, which reveals obvious decadal and multi-decadal oscillation signature. During the last 50 years, the PDO phase transition occurred first in the winter of 1976/1977, and the PDO changed from a cold phase to a warm phase. This regime shift has been reported widely by many previous observational studies on different climatic variables (Nitta and Yamada 1989; Miller et al. 1994; Ebbesmeyer et al. 1991; Francis and Hare 1997; Mantua et al. 1997; Zhu and Yang 2003a). The warm PDO phase has dominated most of the time since 1977 with strong oscillation in 1977-1987, 1991-1997 and 2002-2006, and a cold phase has persisted since 2007, which can be seen more clearly from monthly PDO index. Furthermore, the PDO index has a negative trend over the past 20 years.

Through linear regression upon the above PDO index, typical spatial patterns of wintertime oceanic and atmospheric anomalies in the North Pacific associated with a positive PDO phase are given in Fig. 2. The sea surface temperature anomalies in the North Pacific exhibit a dipole mode during warm PDO phases, with a basin scale cooling anomaly in the western-to-central midlatitude North Pacific and a warming anomaly along the west coast of the North American continent (Fig. 2a). Although PDO is conventionally defined by North Pacific SST anomalies, it does not only exist in the ocean. It is found that the primary patterns of atmospheric circulation anomalies over the North Pacific are well correlated with that of SST anomalies, especially in winter (Davis 1976, 1978; Wallace and Jiang 1987; Kushnir et al. 2002; Zhu and Yang 2003a). The co-variation of oceanic and atmospheric variability in the midlatitude North Pacific also suggests the important role of ocean-atmosphere interaction in the midlatitudes in the generation of PDO. Associated with the basin scale SST cooling, the sea level pressure is anomalously low over the North Pacific (north 

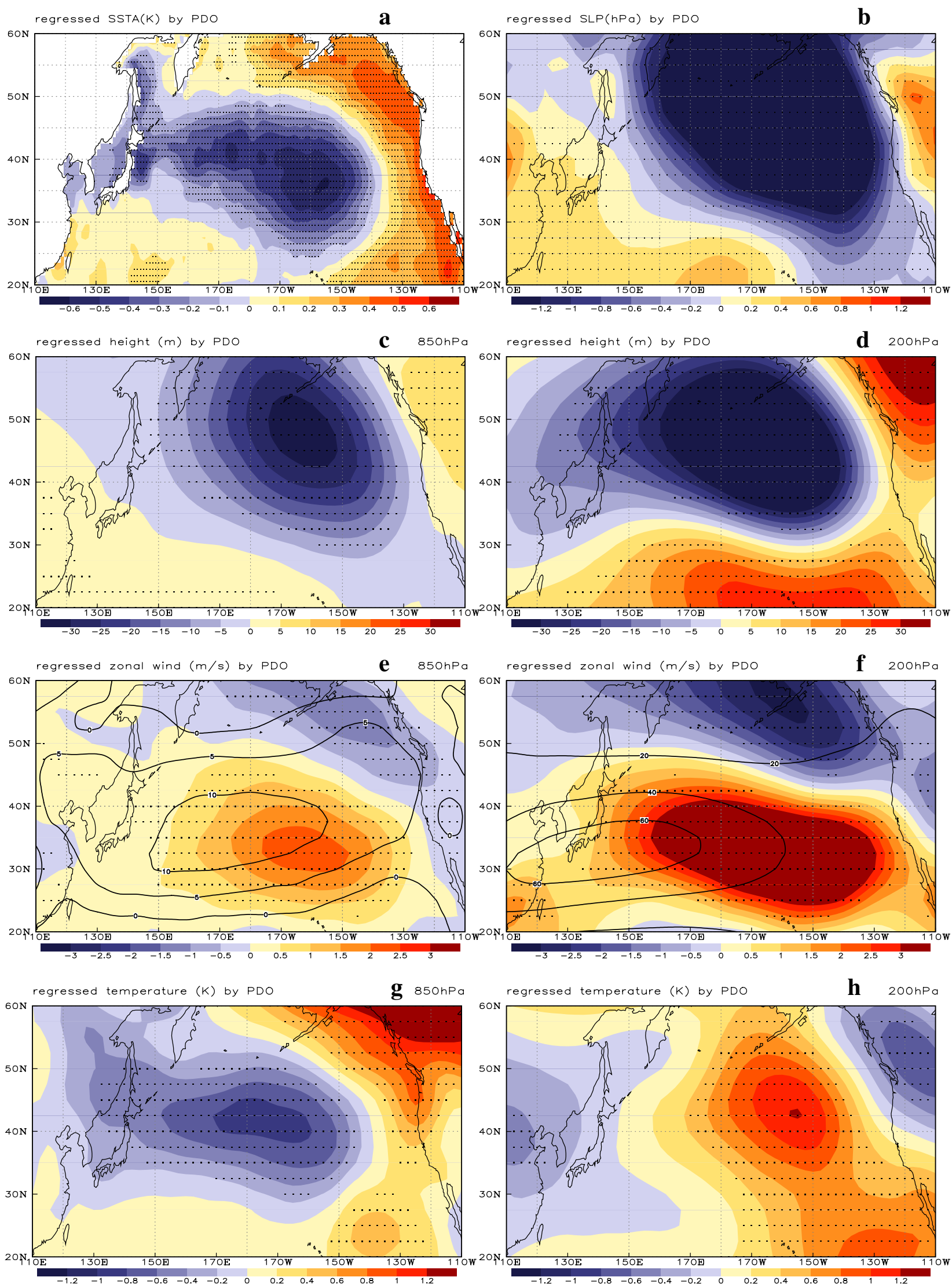
4Fig. 2 Horizontal distribution of the regressed anomalies of a sea surface temperature $(\mathrm{K})$, b sea level pressure $(\mathrm{hPa})$, c $850 \mathrm{hPa}$ geopotential height (m), d $200 \mathrm{hPa}$ geopotential height (m), e $850 \mathrm{hPa}$ zonal wind $(\mathrm{m} / \mathrm{s})$, f $200 \mathrm{hPa}$ zonal wind $(\mathrm{m} / \mathrm{s}), \mathbf{g} 850 \mathrm{hPa}$ air temperature $(\mathrm{K})$, and $\mathbf{h} 200 \mathrm{hPa}$ air temperature $(\mathrm{K})$ upon the standardized PDO index. The black contours in $\mathbf{e}$ and $\mathbf{f}$ represent the climatological values, and the dots indicate the regions passing the $F$ test at $95 \%$ significant level

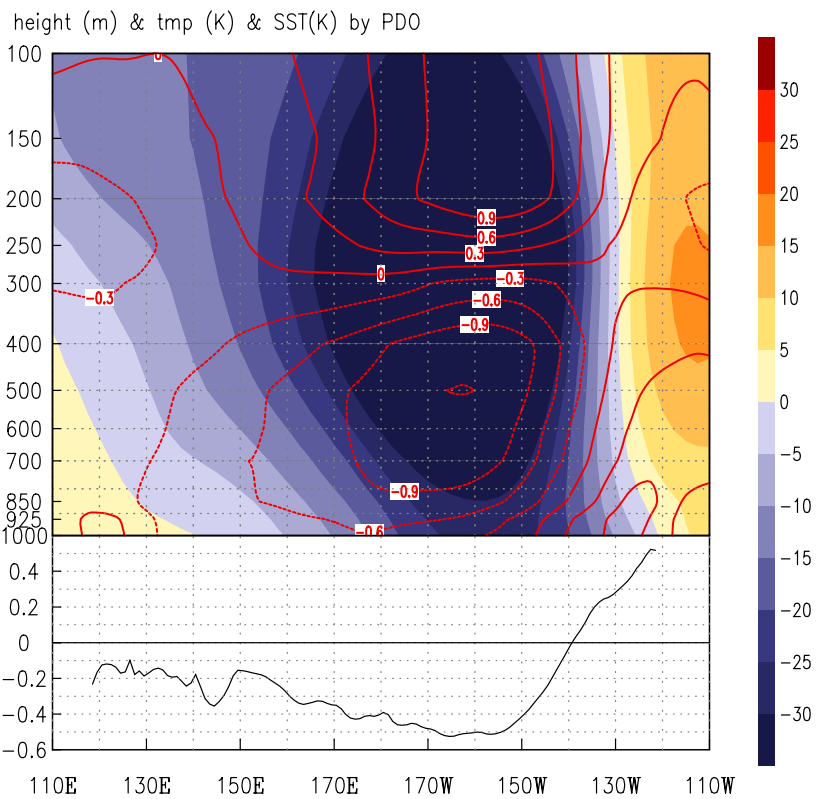

Fig. 3 Longitude-altitude section of the regressed geopotential height (shaded) and air temperature (contours) anomalies (upper panel), as well as the zonal distribution of the regressed sea surface temperature anomalies (lower panel) upon the standardized PDO index, averaged between $35^{\circ} \mathrm{N}$ and $45^{\circ} \mathrm{N}$

of $35^{\circ} \mathrm{N}$ ), indicating that Aleutian Low is enhanced and extends southeastward (Fig. 2b), and the low pressure anomaly center is located north of the cold SST anomaly center. The corresponding spatial patterns of atmospheric geopotential height anomalies in the lower and upper troposphere are both similar to those of SLP anomalies, with large-scale atmospheric low pressure over cold oceanic surface (Fig. 2c, d), featuring a barotropic atmospheric vertical structure. Therefore, the zonal westerly wind (Fig. 2e, f) is strengthened in the zone of maximum geopotential height gradient between $25^{\circ} \mathrm{N}$ and $45^{\circ} \mathrm{N}$ in both low and high levels of atmosphere, right over the cold SST center. However, the atmospheric temperature anomalies associated with the warm PDO phase is characterized by a baroclinic structure in the vertical direction (Fig. 2g, h). In the lower level, there is a negative atmospheric temperature anomaly over the midlatitude North Pacific (Fig. 2g), consistent with the spatial pattern of SST anomalies, while in the higher level the anomalous pattern of atmospheric temperature is opposite (Fig. 2h).
Furthermore, a longitude-altitude section averaged between $35^{\circ} \mathrm{N}$ and $45^{\circ} \mathrm{N}$, as shown in Fig. 3, clearly demonstrates the vertical structure of atmospheric height and temperature anomalies and their relationship with underlying SST anomalies. Over the cold SST anomaly, the anomalous atmospheric geopotential height displays an equivalent barotropic low from surface to above $100 \mathrm{hPa}$ with maximum at $300 \mathrm{hPa}$. Accordingly, the atmospheric temperature becomes anomalously cold below the maximum low center while it is anomalously warm above the center, following the static equilibrium relation. This vertical structure is so-called equivalent barotropic cold/trough structure that describes the unique configuration features of the midlatitude North Pacific ocean-atmosphere anomalies on decadal timescale.

It should be noted that the typical distribution structure of atmospheric anomalies and its relationship with SST anomalies in the midlatitudes is quite different from that in the tropics. In the tropics, the positive SST anomalies trigger deep convection that releases condensational heating. As response to this diabatic heating, the lower-layer atmosphere converges and the upper-layer atmosphere diverges. Therefore, the anomalous atmospheric circulation is characterized by baroclinic structure in the vertical direction, suggesting that the tropical atmospheric anomaly is primarily thermal-driven (Matsuno 1966; Gill 1980). While in the midlatitudes, the atmospheric height anomaly is equivalent barotropic with a geopotential low over cold water. The equivalent barotropic structure and the cold-trough relationship are not consistent with our knowledge of thermaldriven circulation. It is thus indicated that the midlatitude atmospheric circulation anomalies should be driven not only by the direct diabatic heating and that the mechanism of ocean-atmosphere interaction in the midlatitudes should be different from that in the tropics. In the following sections, we further examine the causative and maintenance mechanism of the equivalent barotropic cold/trough structure and the associated processes of midlatitude oceanatmosphere interaction.

\section{The atmospheric forcing on the ocean in the midlatitude North Pacific}

As shown in Fig. 2e, f, corresponding to the cold SST anomaly in the central North Pacific, the westerly is intensified from surface to upper atmosphere. On one hand, the intensified surface westerly tends to increase surface sensible and latent heat fluxes from the ocean, and hence increase upward surface heat flux (in wintertime, total surface heat flux is dominated by surface turbulent heat flux) over the eastern-to-central North Pacific (Fig. 4a). Since the ocean loses more heat to the atmosphere, the SST will 

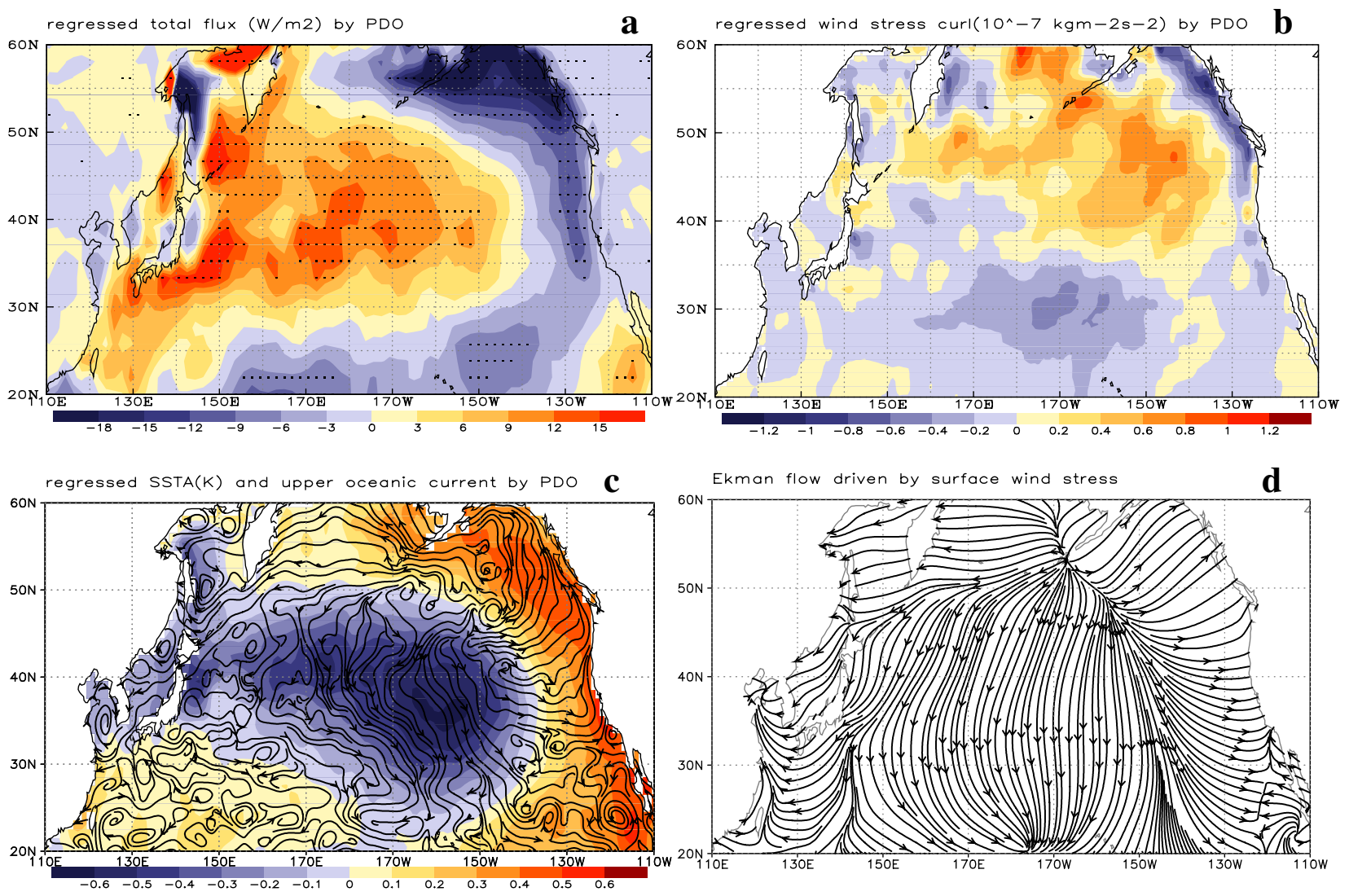

Ekman flow driven by surface wind stress

d
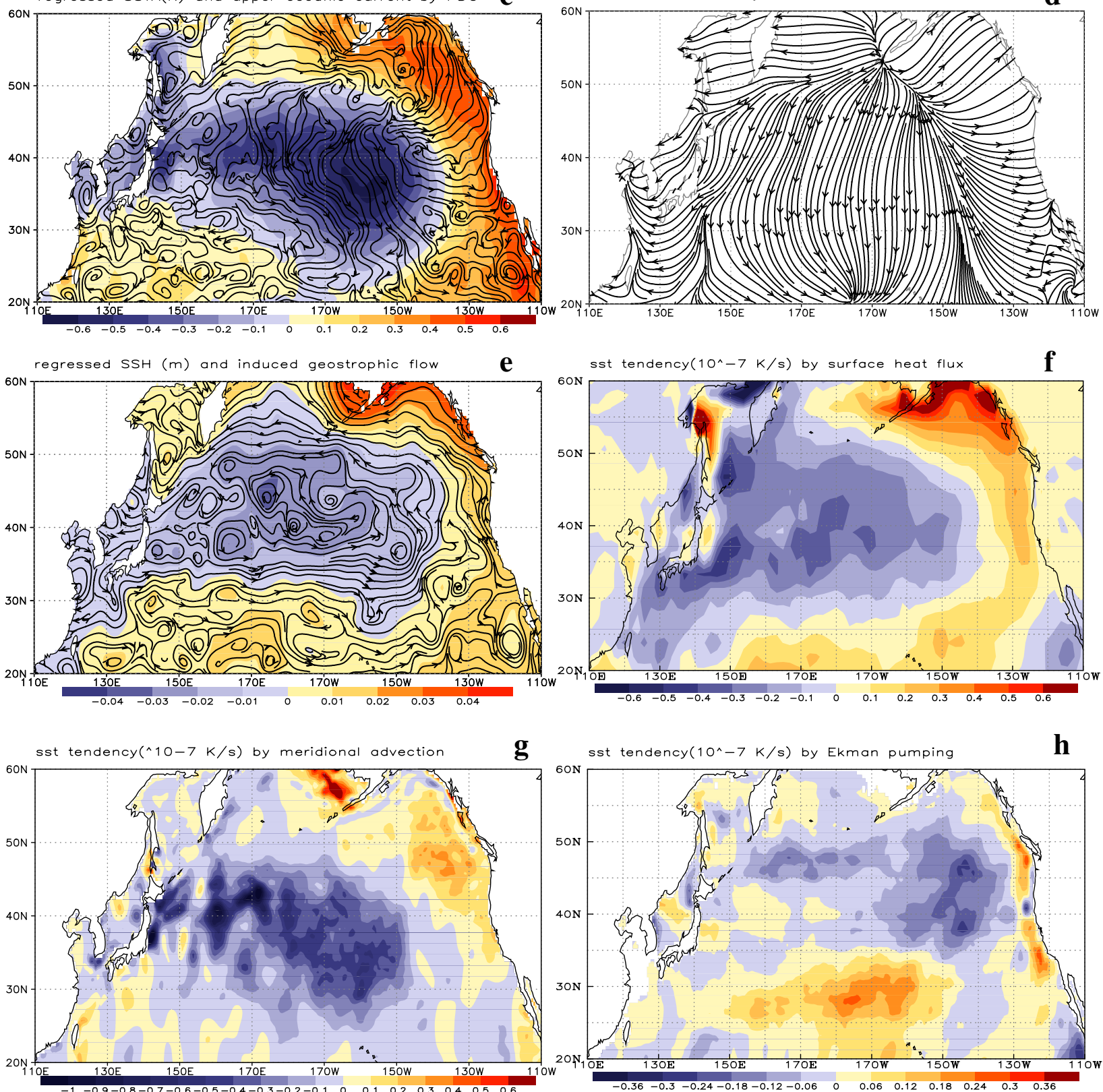

gst tendency $\left(10^{\wedge}-7 \mathrm{k} / \mathrm{s}\right)$ by Ekman pumping

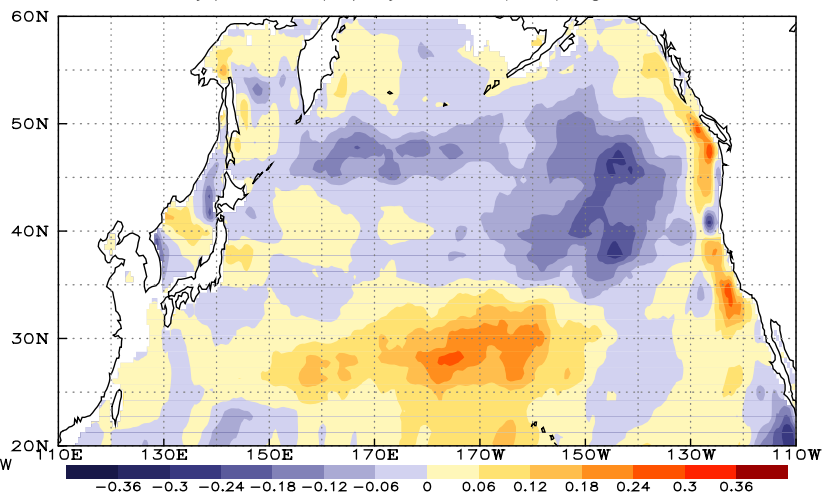


4Fig. 4 As in Fig. 2, but for a upward surface heat flux $\left(\mathrm{Wm}^{-2}\right)$, b surface wind stress curl $\left(10^{-7} \mathrm{~kg} \mathrm{~m}^{-2} \mathrm{~s}^{-2}\right)$, c upper oceanic current together with sea surface temperature (K, shaded), d Ekman current, e geostrophic current together with sea surface height (shaded), and SST tendencies $\left(10^{-7} \mathrm{Ks}^{-1}\right)$ induced by $\mathbf{f}$ surface heat flux, $\mathbf{g}$ meridional current anomaly advection, and $\mathbf{h}$ Ekman pumping, respectively

be further reduced. On the other hand, a cyclonic surface wind stress curl anomaly (Fig. 4b) generated north of the increased surface westerly tends to drive an upper (0-100 m averaged) oceanic horizontal current anomaly (Fig. 4c) characterized by a cyclonic curl in the eastern North Pacific and a large-area southward flow in the western-to-central North Pacific, and an upward Ekman pumping anomaly. The upper oceanic horizontal current anomaly includes two components: the Ekman current anomaly (Fig. 4d) in accordance to the Ekman theory and the geostrophic current anomaly (Fig. 4e) determined by the slope of sea surface height anomaly that is caused by the divergence of Ekman transport, but the Ekman current anomaly is dominant. The southward Ekman flow and upward Ekman pumping could both transport cold water into the region of cold SST anomaly and further strengthen the SST anomaly there.

Suppose that the climatological SST gradient exists only in meridional direction and that the initial SST anomaly is zero, then the anomalous SST tendency can be written as, $\partial T^{\prime} / \partial t=-v^{\prime} \partial \bar{T} / \partial y-w_{e}^{\prime} \partial \bar{T} / \partial z+Q^{\prime} /\left(\rho c_{p} H\right)$, where the over bar denotes wintertime climatology and the prime denotes the PDO-related wintertime anomaly. We estimate the SST tendency induced by the anomalies of surface heat flux $\left(Q^{\prime} /\left(\rho c_{p} H\right)\right)$, meridional current advection $\left(-v^{\prime} \partial \bar{T} / \partial y\right)$ and Ekman pumping $\left(-w_{e}^{\prime} \partial \bar{T} / \partial z\right)$, respectively, to analyze the relative contributions of the three processes to the cold SST anomaly (Fig. 4f-h). We can see that all the three processes can cause large-scale SST cooling in the North Pacific. However, the contributions of surface heat flux anomaly (Fig. 4f) and meridional advection anomaly especially that by southward Ekman flow anomaly (Fig. 4g) are more substantial, while the SST changes induced by Ekman pumping anomaly is relatively small (Fig. 4h). Therefore, through the thermodynamic and dynamical processes forced by the increased surface westerly, the original cold SST anomaly will be maintained or even enhanced, forming a positive feedback if the increased surface westerly is induced by the cold SST anomaly.

Here we find that though the cold-trough relationship in the midlatitudes is different from the warm-trough relationship in the tropics, they are both associated with an upward surface heat flux. In the tropics, the upward heat flux is caused by warm SST and thus the warm water is the forcing source of the atmosphere. However, in the midlatitude North Pacific, it can be understood that the cold water is actually a result of atmospheric forcing. That is why the midlatitude ocean has been considered to play a passive role in the ocean-atmosphere interaction for a long time (Hasselmann 1976; Frankignoul et al. 1997; Saravanan and McWilliams 1998; Weng and Neelin 1998). Though there is considerable evidence from observations, theoretical analyses and GCM simulations that the extratropical SST anomaly has an impact on the large-scale atmospheric circulation, to what extent and in what way the basin scale SST anomaly could influence the atmosphere is still unclear.

\section{The atmospheric response to the ocean in the midlatitude North Pacific}

\subsection{Forcing sources of midlatitude seasonal-mean atmospheric circulation}

As we mentioned in Sect. 3, the impact of midlatitude oceanic anomaly on the atmosphere may not only through direct diabatic heating. In the midlatitudes, the atmosphere is characterized by jet stream and associated intensive transient eddy activities. The transient eddies can redistribute heat and momentum in the atmosphere, and thus can drive or maintain the general circulation. The forcing terms of seasonal-mean atmospheric circulation in the midlatitudes can be determined in terms of the quasi-geostrophic potential vorticity (QGPV) equation that can be written as,

$$
\begin{aligned}
& \left(\frac{\partial}{\partial t}+\overline{\vec{V}}_{h} \cdot \nabla\right)\left[\frac{1}{f} \nabla^{2} \bar{\Phi}+f+\frac{\partial}{\partial p}\left(\frac{f}{\sigma_{1}} \frac{\partial \bar{\Phi}}{\partial p}\right)\right] \\
& =-f \frac{\partial}{\partial p}\left(\frac{\alpha}{\sigma_{1}} \frac{\bar{Q}_{d}}{\bar{T}}\right)-f \frac{\partial}{\partial p}\left(\frac{\alpha}{\sigma_{1}} \frac{\bar{Q}_{e d d y}}{\bar{T}}\right)+\bar{F}_{e d d y}
\end{aligned}
$$

where the overbar denotes the seasonal mean, $\Phi$ is the geopotential, $\vec{V}_{h}$ the geostrophic wind, $T$ the temperature, and $\sigma_{1}$ the static stability parameter. $\bar{Q}_{d}$ is the seasonal-mean diabatic heating that can be diagnosed as a residual of the thermodynamic equation (Yanai and Tomita 1998), $\bar{Q}_{e d d y}$ is defined as the seasonal-mean transient eddy heating that is determined by the 3-dimensional convergence of heat flux transport by transient eddies,

$\bar{Q}_{e d d y}=-\nabla \cdot \overline{\overrightarrow{V_{h}^{\prime} T^{\prime}}}-\frac{\partial \overline{\omega^{\prime} T^{\prime}}}{\partial p}+\frac{R}{c_{p} p} \overline{\omega^{\prime} T^{\prime}}$,

where the prime denotes the departure from the seasonal mean. $\bar{F}_{\text {eddy }}$ is the transient eddy vorticity forcing that is determined by the convergence of vorticity flux transport by transient eddies,

$$
\bar{F}_{e d d y}=-\nabla \cdot \overline{\vec{V}_{h}^{\prime} \zeta^{\prime}} .
$$



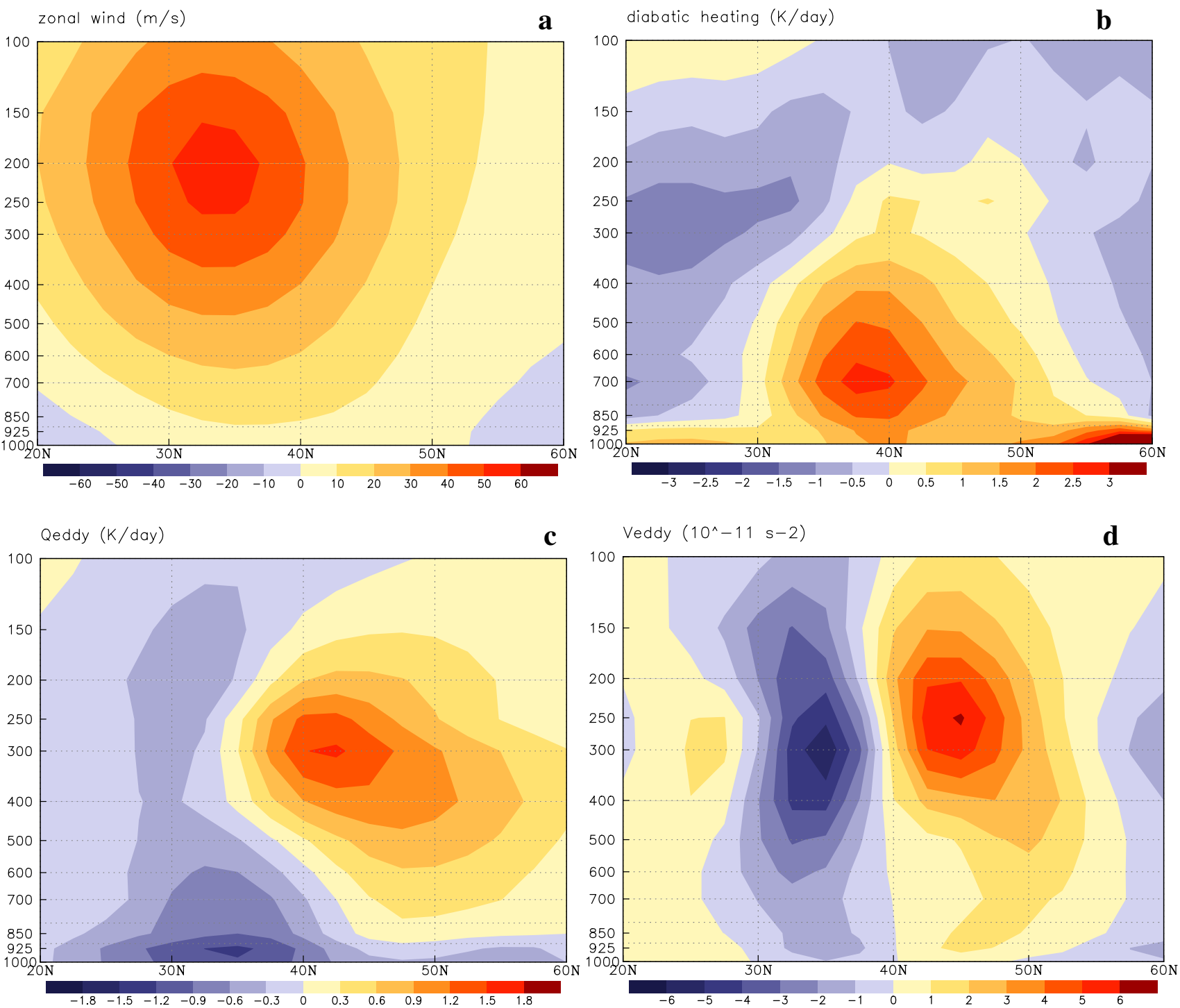

Fig. 5 Latitude-altitude sections of the wintertime climatology of a zonal wind ( $\mathrm{m} / \mathrm{s})$, b diabatic heating (K/day), $\mathbf{c}$ transient eddy heating (K/ day), and $\mathbf{d}$ transient eddy vorticity forcing $\left(10^{-11} \mathrm{~s}^{-2}\right)$, averaged between $150^{\circ} \mathrm{E}$ and $150^{\circ} \mathrm{W}$

It can be found out from the right-hand terms of Eq. (1) that there are three terms that can generate atmospheric potential vorticity (PV) sources to change the seasonalmean atmospheric circulation: the diabatic heating, the transient eddy heating, and the transient eddy vorticity forcing. The former two terms are proportional to the vertical gradient of the heating, and the third term will be positive (negative) if there is a convergence (divergence) of the eddy vorticity flux within a certain region. Therefore, the seasonal-mean atmospheric circulation is driven by both thermal and dynamical forcing, and the transient eddy activities can influence the seasonal-mean atmospheric circulation by transporting both heat and vorticity fluxes. It is conceivable that the midlatitude ocean thermal condition can affect the atmosphere in two ways: the direct thermal forcing by diabatic heating and the indirect thermal and dynamical forcing by atmospheric transient eddy activities.

Climatologically, the relationship between the atmospheric transient eddy activities and the mean flow were previously identified with zonal averages over whole Northern Hemisphere (Holopainen et al. 1982; Lau and Holopainen $1984)$. Here, the impact of the diabatic heating $\left(\bar{Q}_{d}\right)$, transient eddy heating $\left(\bar{Q}_{e d d y}\right)$ and transient eddy vorticity forcing $\left(\bar{F}_{e d d y}\right)$ on the seasonal-mean atmosphere over the midlatitude North Pacific can be understood also from the climatological view (Fig. 5). A striking feature of wintertime seasonal-mean atmosphere over the midlatitude North Pacific is the westerly jet throughout the entire troposphere (Fig. 5a). The wintertime westerly jet over the North Pacific is a combination of the subtropical jet and the midlatitude 
eddy-driven jet. It can be seen from Fig. 5a that the westerly has a maximum located around $32^{\circ} \mathrm{N}$ at the upper troposphere, featuring the subtropical jet, while that around and north of $40^{\circ} \mathrm{N}$, particularly at the lower troposphere, the westerly is basically eddy-driven. Driven by surface westerly wind, the western boundary oceanic currents and their extensions transfer heat to the atmosphere via sensible and latent heat fluxes, generating atmospheric diabatic heating over the region north of the jet axis where Aleutian low controls (Fig. 5b). However, the diabatic heating is relatively weak and centered below the middle troposphere, with a maximum at $700 \mathrm{hPa}$, unlike in the tropics where it is determined by the convection-induced latent heat release and thus much deeper. In terms of Eq. (1), this shallow diabatic heating tends to generate a positive PV source near the surface which can reinforce the surface westerly, and a negative PV source above $700 \mathrm{hPa}$ which can reduce the westerly there. Meanwhile, the poleward and upward thermal transport by the transient eddy activities diverges south of the jet axis, producing a "cooling" near the surface, while converges north of the jet axis, producing a "heating" with a maximum at $300 \mathrm{hPa}$ (Fig. 5c). Such a transient eddy heating centered at the mid-troposphere as one of the PV sources in Eq. (1) can affect seasonal-mean jet in a way similar to the diabatic heating, but tends to more easily create a baroclinic atmospheric response than the shallow diabatic heating as shown in Fig. 5 b.

Besides the heat flux, transient eddies also transport vorticity flux in upper troposphere. The convergence of vorticity flux by transient eddy activities is a vorticity source and thus one of the PV sources for the seasonal-mean atmosphere. Over the North Pacific, the climatological transient eddy vorticity transport produces a dipole PV source about around $40^{\circ} \mathrm{N}$ that can be considered as the eddy-driven jet axis, with a positive (negative) source north (south) of $40^{\circ} \mathrm{N}$ (Fig. 5d). The transient eddy vorticity forcing has an equivalent barotropic structure in the vertical direction, with large values in the upper troposphere. The transient eddy vorticity forcing is always orthogonal to the eddy-driven jet axis, with positive values in the polar side of jet and negative values in the equatorial side, thus maintaining the jet throughout the troposphere. Such a role of the transient eddy vorticity forcing is generally considered to be typical in Southern Hemisphere where the midlatitude jet is mostly eddy-driven. However, over the North Pacific, the eddy-driven jet and the subtropical jet emerge together in winter. The jet core mainly represents the subtropical jet, while the surface westerly at around $40^{\circ} \mathrm{N}$ actually indicates the location of eddy-driven jet.

Furthermore, we find that the transient eddy activities are closely related to the oceanic front zones. As a result of oceanic adjustment to the surface westerly, an anticyclone
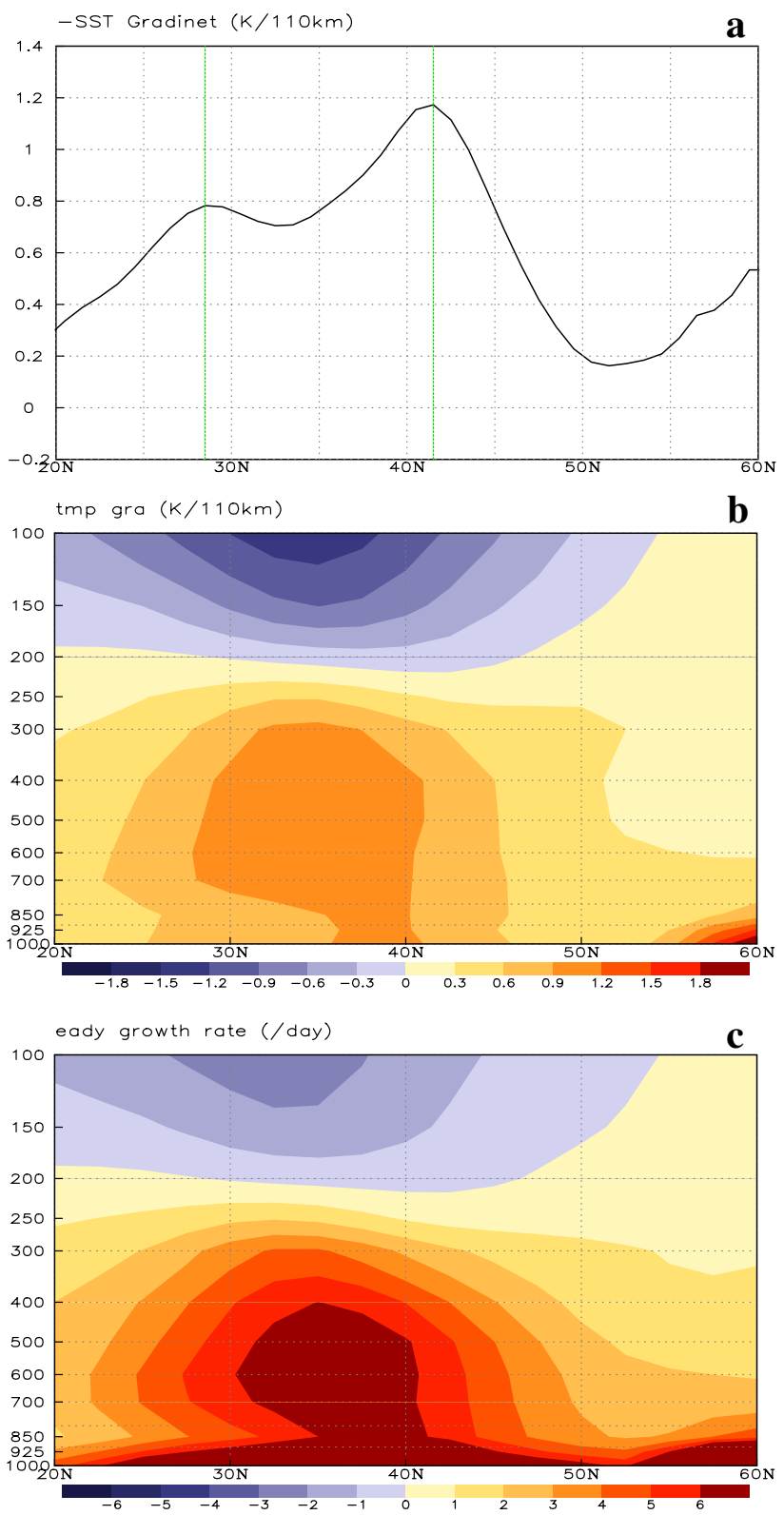

Fig. 6 As in Fig. 5, but for a meridional sea surface temperature gradient $(\mathrm{K} / 110 \mathrm{~km})$, b meridional air temperature gradient $(\mathrm{K} / 110 \mathrm{~km})$, and $\mathbf{c}$ Eady growth rate $\left(\right.$ day $\left.^{-1}\right)$

subtropical gyre and a cyclonic subpolar gyre come into being. Due to the confluence of warm and cold currents in the western boundary, two narrow zones with larger SST gradient are generated at around $30^{\circ} \mathrm{N}$ and $42^{\circ} \mathrm{N}$, which are so-called subtropical and subpolar oceanic front zone, respectively (Fig. 6a), just below the westerly jet (Fig. 5a). Resultantly, a large meridional gradient of the lowerlevel atmospheric temperature, i.e., the atmospheric front zone, is formed just above the oceanic fronts (Fig. 6b). It is the atmospheric front zone that causes an atmospheric 

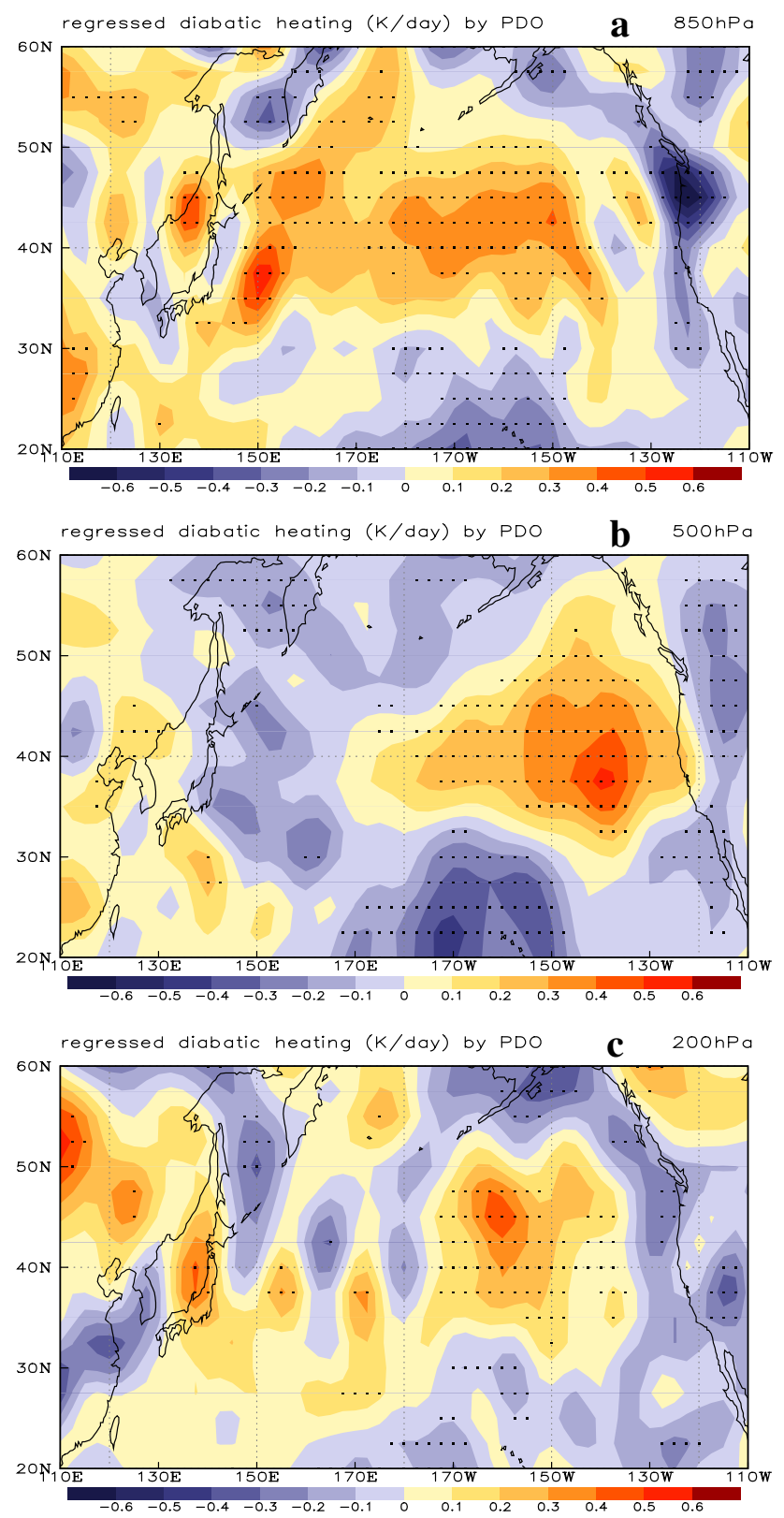

Fig. 7 As in Fig. 2, but for diabatic heating (K/day) at a $850 \mathrm{hPa}, \mathbf{b}$ $500 \mathrm{hPa}$, and c $200 \mathrm{hPa}$, respectively

baroclinicity zone (Fig. 6c) in which baroclinic eddies can generate.

Overall, above analyses suggest that the climatological state over the North Pacific is an equilibrium state involving the processes of ocean-atmosphere interaction in the midlatitudes. In such an air-sea interaction, the ocean affects the atmosphere mostly through the oceanic front zone. The oceanic front zone determines the low-level atmospheric baroclinicity that generates the transient eddies. Then, the transient eddy activities feedback on the seasonal-mean westerly flow, which, in turn, affects the ocean.
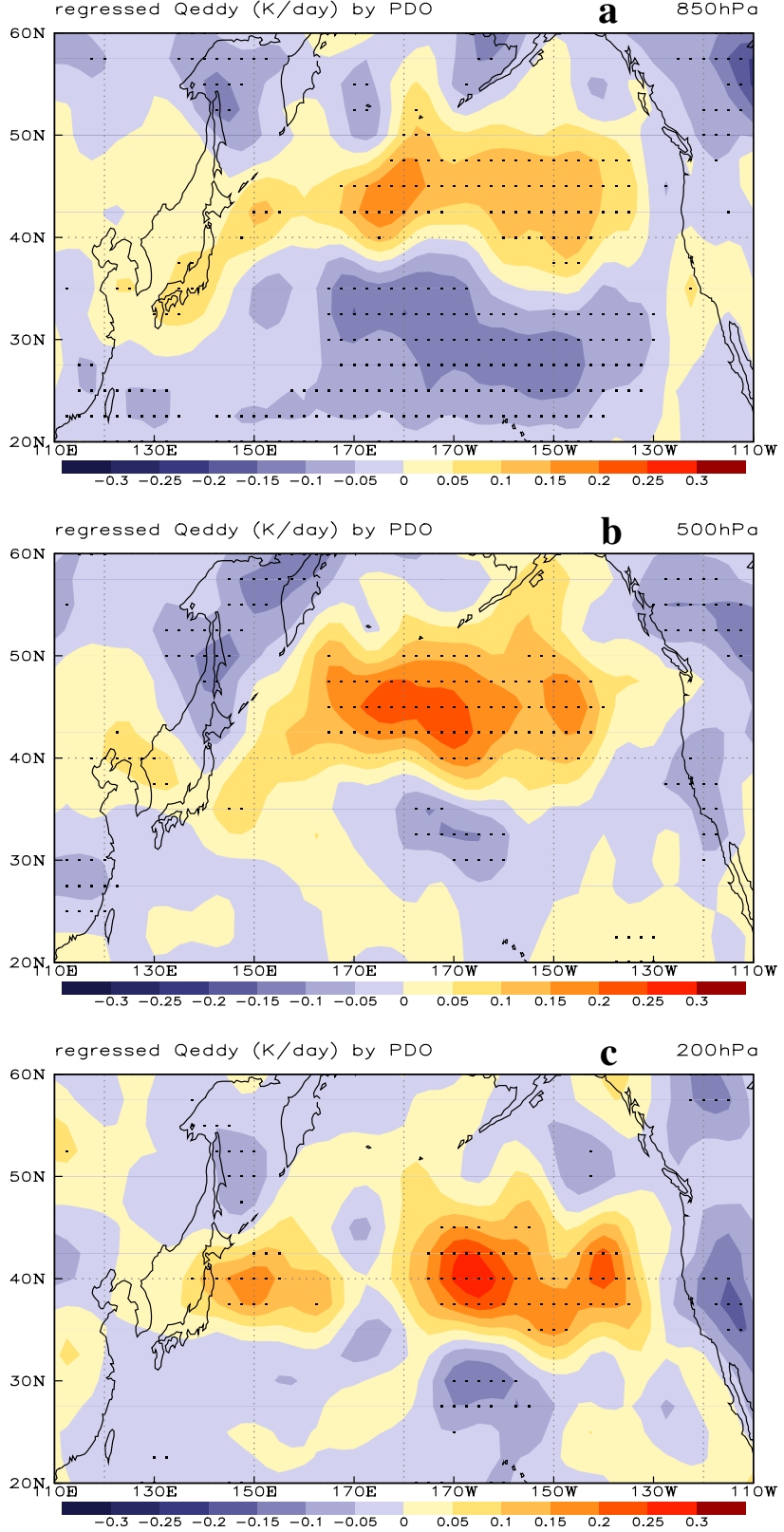

Fig. 8 As in Fig. 2, but for transient eddy heating (K/day) at a $850 \mathrm{hPa}, \mathbf{b} 500 \mathrm{hPa}$, and c $200 \mathrm{hPa}$, respectively

\subsection{Relative role of different forcing sources in decadal climate anomalies}

In Sect. 3, we have identified the decadal climate anomalies associated with the PDO. To understand the mechanism responsible for the decadal climate anomalies, here we further identify the decadal anomalies of the forcing sources including the diabatic heating, transient eddy heating and transient eddy vorticity forcing over the North Pacific. Figures 7, 8 and 9 show the horizontal distribution of the regressed diabatic heating, transient eddy heating, 

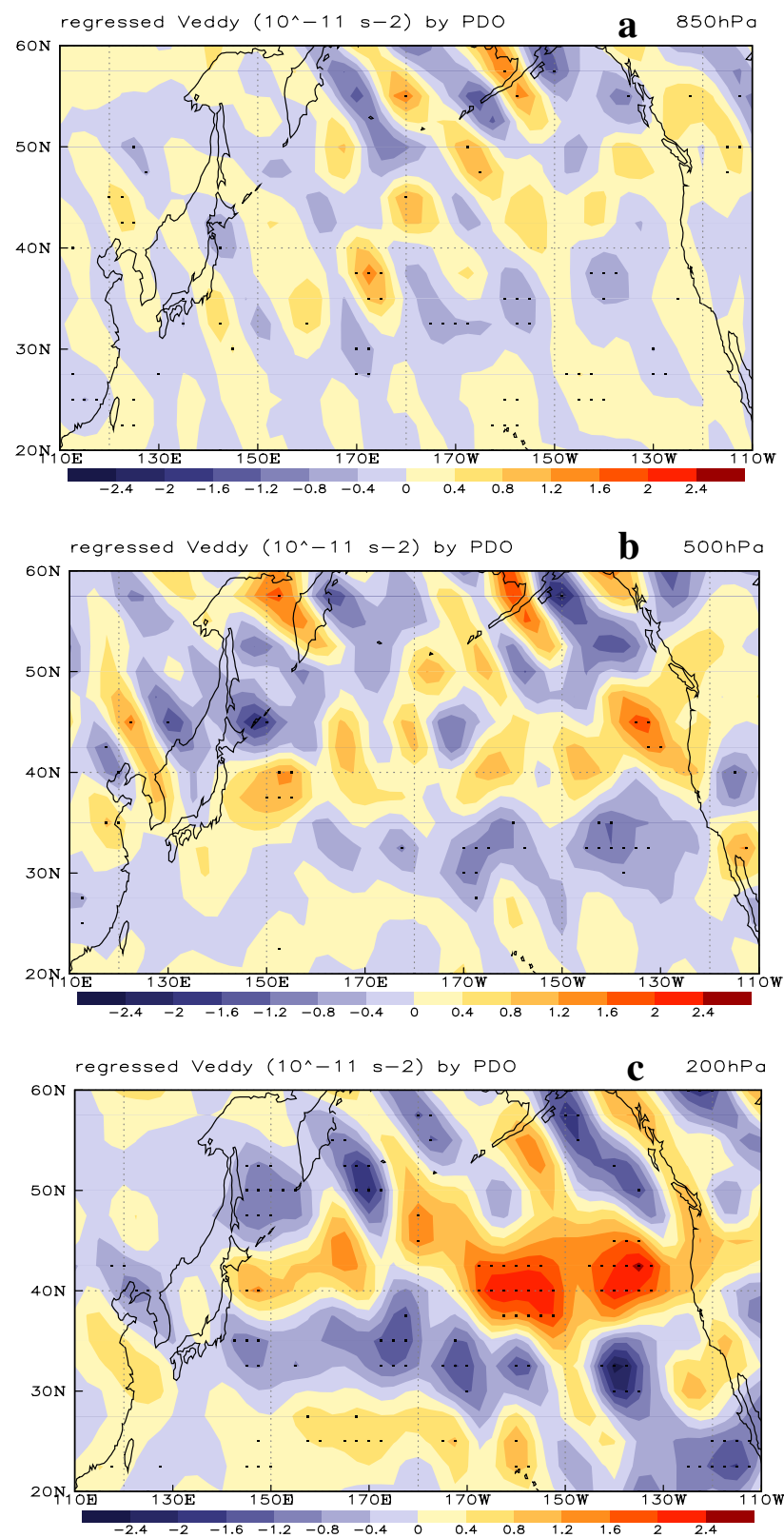

Fig. 9 As in Fig. 2, but for transient eddy vorticity forcing $\left(10^{-11}\right.$ $\mathrm{s}^{-2}$ ), at a $850 \mathrm{hPa}, \mathbf{b} 500 \mathrm{hPa}$, and c $200 \mathrm{hPa}$, respectively

and transient eddy vorticity forcing anomalies, respectively, and Figs. 10 and 11 show the latitude-altitude section averaged between $150^{\circ} \mathrm{E}$ and $150^{\circ} \mathrm{W}$ of these anomalies as well as the decadal anomalies of other atmospheric and oceanic variables, respectively. One of the striking features is that the decadal anomalies (shaded) shown in those figures are mostly in phase with the climatology (contours), suggesting a decadal strengthening corresponding to a warm PDO phase. We can see that after the regime shift in 1976/77, the diabatic heating increases over the central-to-eastern North Pacific between $30^{\circ}$ and $50^{\circ} \mathrm{N}$ at all levels (Figs. 7, 10a), especially at the lower levels, due to the enhancement of oceanic heat release resulting from strengthened surface westerly (Fig. 10d). The low-level positive diabatic heating anomaly is basin scale (Fig. 7a), and its distribution pattern is similar to that of surface heat flux (Fig. 4a). As altitude increases, the diabatic heating anomaly shifts eastward, probably due to the different type of the heat sources from the west to the east. Over the west where the underlying ocean is warmer due to Kuroshio Current, the diabatic heating anomaly could be mostly related to the surface heat flux anomaly. However, over the central-to-eastern North Pacific, the increased diabatic heating may be mostly contributed from the precipitation-induced latent heat release anomaly that is associated with the intensified Aleutian Low (Fig. 2b). Since the atmospheric stratification is overall stable over this region, the heating cannot develop deeply. Hence the heating anomaly is confined to middle-to-lower troposphere (Fig. 10a). Furthermore, the diabatic heating anomaly is almost in phase with the equivalent barotropic geopotential low in the meridional direction (Fig. 10e).

When the underlying SST becomes cooler after the regime shift (Figs. 2a, 11a), the meridional gradient of SST increases south of $40^{\circ} \mathrm{N}$ and decrease north of $40^{\circ} \mathrm{N}$ (Fig. 11b). Correspondingly, the meridional gradient of low-level atmospheric temperature and the atmospheric baroclinicity both increase south of $40^{\circ} \mathrm{N}$ and decrease north of $40^{\circ} \mathrm{N}$ (Fig. 11c, d), and so does the associated northward heat flux transport by transient eddies. The heat flux converges between the positive and negative anomalies of baroclinicity. As a result, the PDO-regressed transient eddy heating anomaly has a positive center over the midlatitude North Pacific between $35^{\circ} \mathrm{N}$ and $60^{\circ} \mathrm{N}$. The heating anomaly is deep and robust nearly in the whole troposphere with maximum at around $300 \mathrm{hPa}$ (Figs. 8, 10b), also in phase with the atmospheric geopotential low meridionally (Fig. 10e). The magnitude of transient eddy heating anomaly is comparable to that of diabatic heating, which also illustrates that transient eddy heating is as important as diabatic heating in the middle and high latitudes. In terms of the total heating, its maximum is located at the upper level of atmosphere around $300 \mathrm{hPa}$, dominated by transient eddy heating. While in the middle and lower layers, the total heating is dominated by diabatic heating.

The transient eddy vorticity forcing anomalies are characterized by a positive anomaly in the upper troposphere over the central to eastern North Pacific between $35^{\circ} \mathrm{N}$ and $50^{\circ} \mathrm{N}$ and a negative anomaly between $25^{\circ} \mathrm{N}$ and $35^{\circ} \mathrm{N}$ (Figs. 9, 10c). In the vertical direction, the transient eddy vorticity forcing anomalies also display an equivalent barotropic structure, which is weak in middle and lower troposphere and increases with height. The anomaly center is at $250 \mathrm{hPa}$, almost in phase with the atmospheric geopotential low as shown in Fig. 10e. 

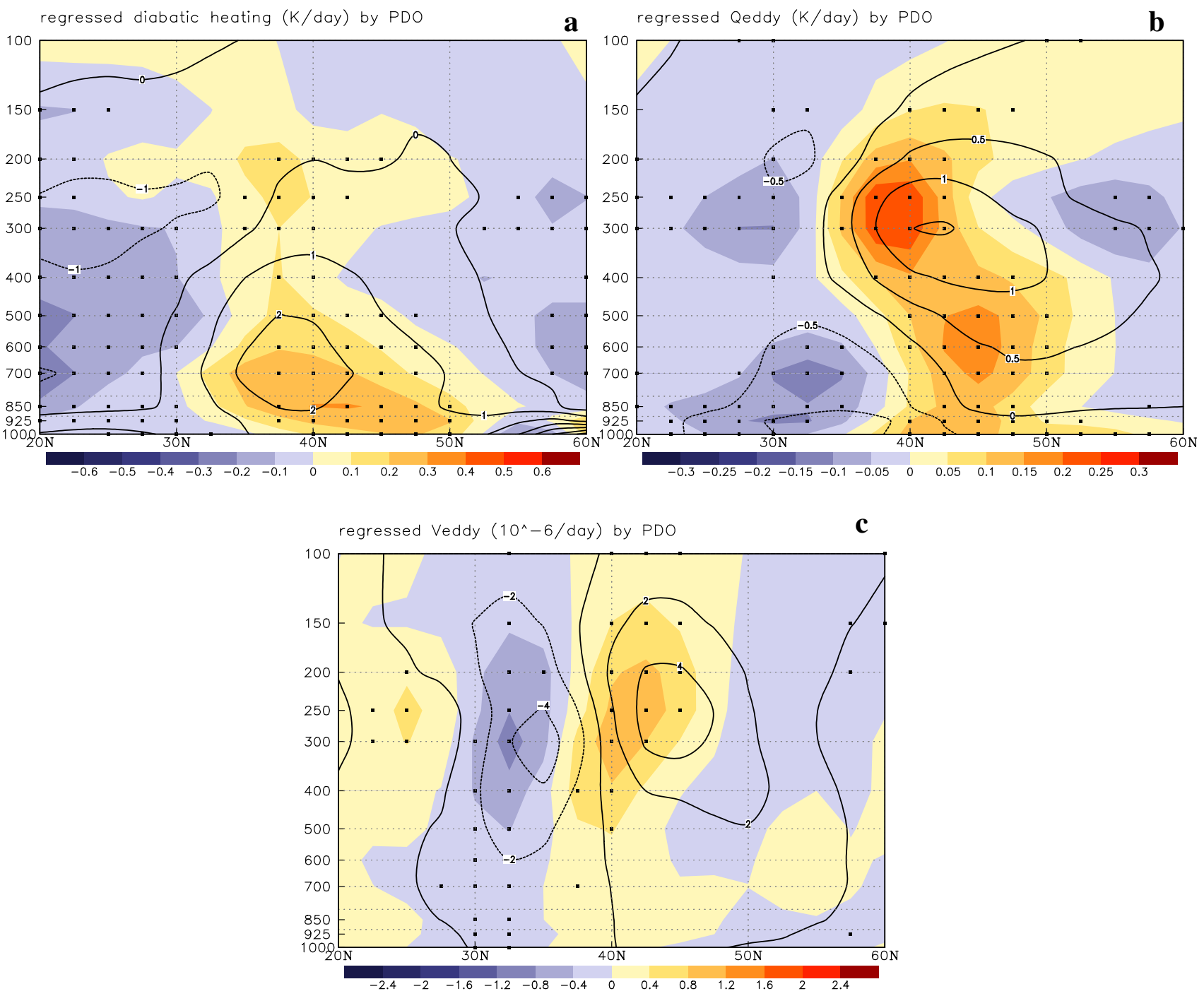

regressed zonal wind $(\mathrm{m} / \mathrm{s})$ by PDO

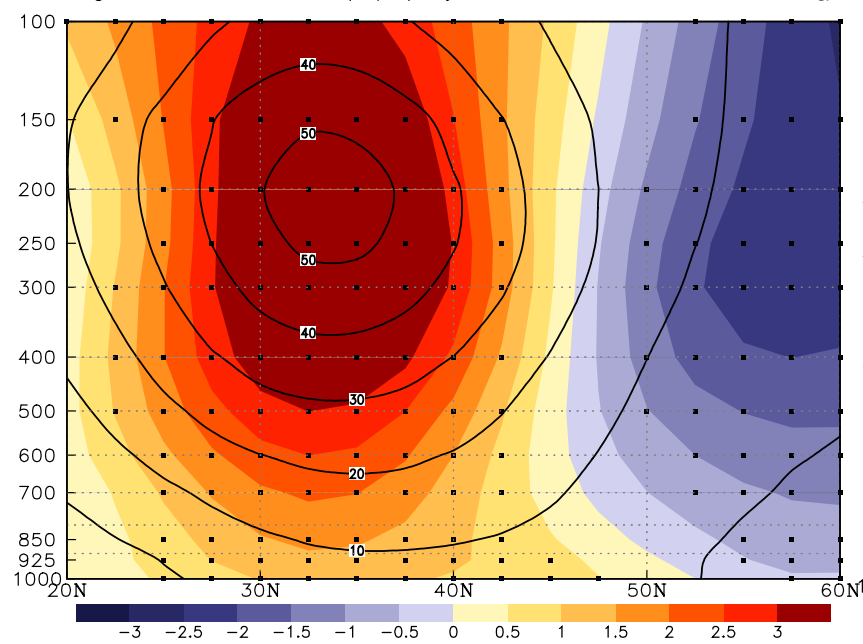

Fig. 10 Latitude-altitude sections of the regressed anomalies of a diabatic heating, $\mathbf{b}$ transient eddy heating, $\mathbf{c}$ transient eddy vorticity forcing, $\mathbf{d}$ zonal wind, and e geopotential height, averaged between d regressed height $(m)$ by PDO

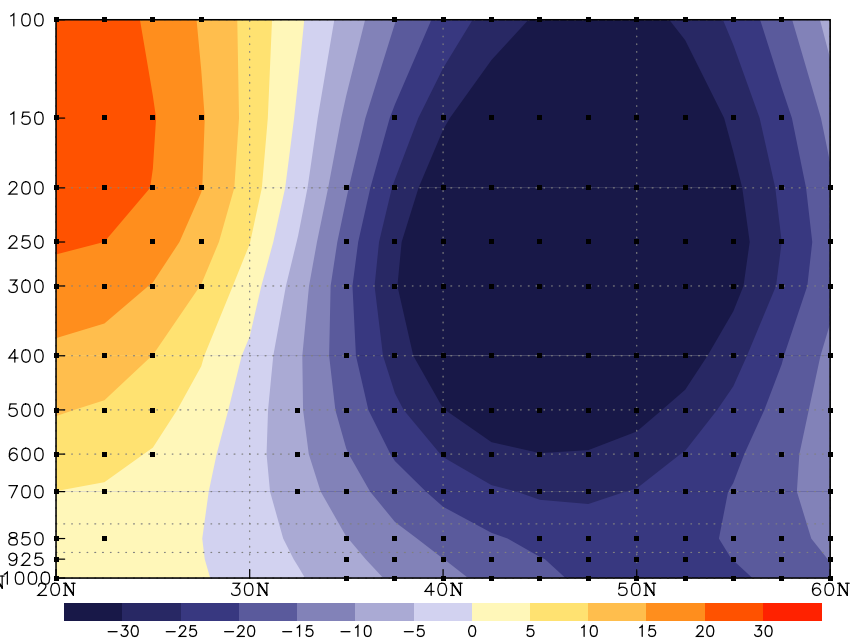

$150^{\circ} \mathrm{E}$ and $150^{\circ} \mathrm{W}$. The black contours represent the climatological mean values, and the dots indicate the regions passing the $F$-test at $95 \%$ significant level 

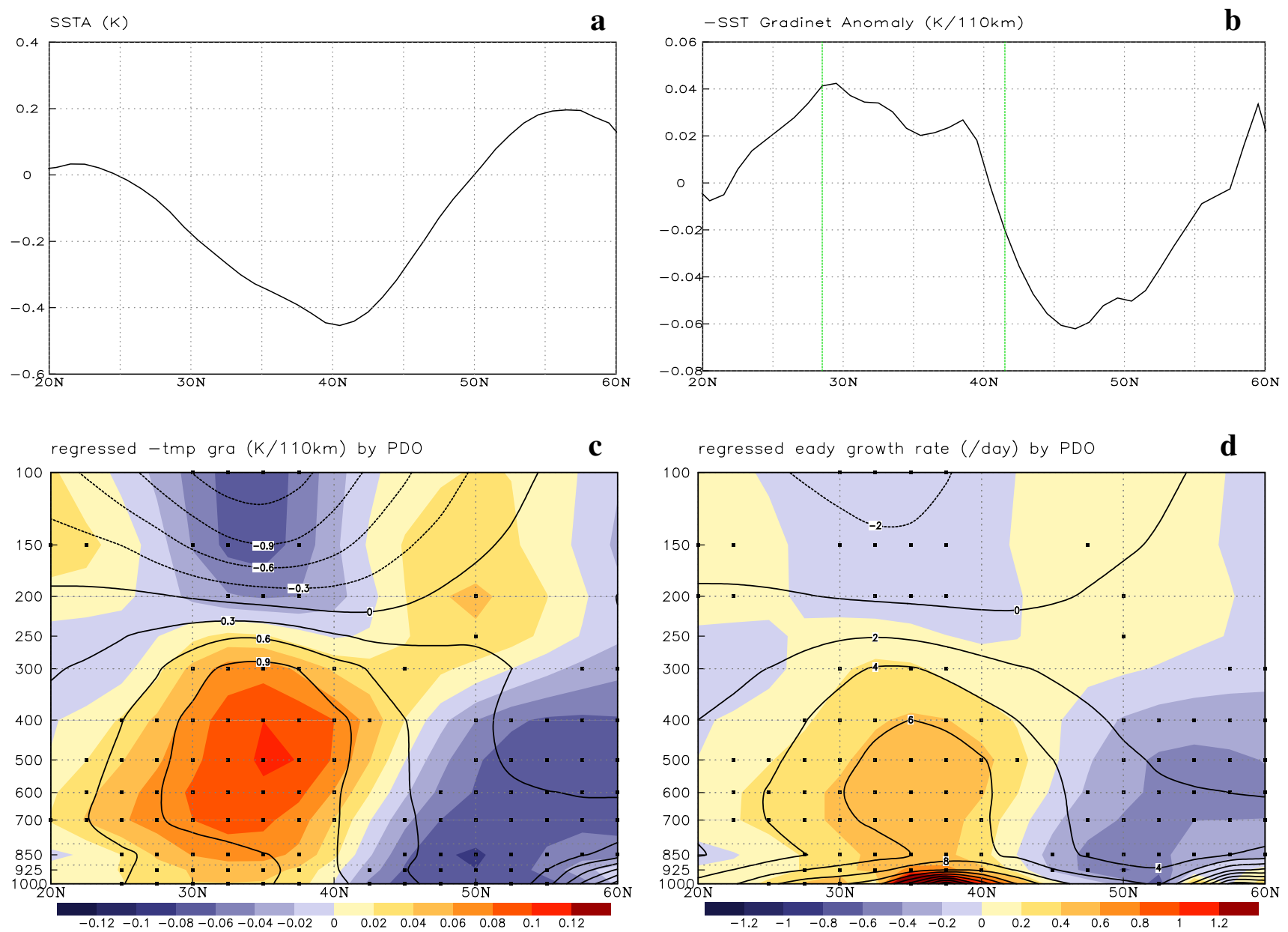

Fig. 11 Meridional distribution of the regressed anomalies of a sea surface temperature, and $\mathbf{b}$ meridional sea surface temperature gradient, as well as latitude-altitude sections of the regressed anomalies of c meridional air temperature gradient, and $\mathbf{d}$ Eady growth rate, aver-

aged between $150^{\circ} \mathrm{E}$ and $150^{\circ} \mathrm{W}$. The black contours in $\mathbf{c}$ and $\mathbf{d}$ represent the climatological mean values, and the dots indicate the regions passing the $F$-test at $95 \%$ significant level

The atmospheric response to the thermal and dynamical forcing can be examined based on the following geopotential tendency equation that is derived from QGPV equation, Eq. (1) (Lau and Holopainen 1984) $\left(F_{1}\right.$ and $\left.F_{2}\right)$ that are proportional to the vertical gradient of diabatic heating and transient eddy heating, respectively, and compare them with transient eddy vorticity

$\left(\frac{1}{f} \nabla^{2}+\frac{f}{\sigma_{1}} \frac{\partial^{2}}{\partial p^{2}}\right)\left(\frac{\partial \Delta \bar{\Phi}}{\partial t}\right)=\underbrace{-f \frac{\partial}{\partial p}\left(\frac{\alpha}{\sigma_{1}} \frac{\Delta \bar{Q}_{d}}{\bar{T}}\right)}_{F_{1}} \underbrace{-f \frac{\partial}{\partial p}\left(\frac{\alpha}{\sigma_{1}} \frac{\Delta \bar{Q}_{e d d y}}{\bar{T}}\right)}_{F_{2}} \underbrace{+\Delta \bar{F}_{e d d y}}_{F_{3}}+R_{v}$,

where $\Delta$ denotes the seasonal anomaly, $\partial \Delta \bar{\Phi} / \partial t$ is the initial geopotential tendency, and $R_{v}$ is considered to be a residual term including the horizontal advection of quasigeostrophic potential vorticity and the friction. According to Eq. (4), the initial geopotential tendency is proportional to the vertical gradient of the heating, and to the transient eddy vorticity forcing. forcing $\left(F_{3}\right)$ (Fig. 12). Different from the equivalent barotropic structure of $F_{3}$ (Fig. 12c), $F_{1}$ and $F_{2}$ both display baroclinic structure in the vertical direction, with positive anomaly below the maximal heating and negative anomaly above the maximal heating (Fig. 12a, b). The combined forcing of $F_{1}, F_{2}$ and $F_{3}$ also shows a barotropic positive anomaly between $35^{\circ} \mathrm{N}$ and $45^{\circ} \mathrm{N}$ that is 


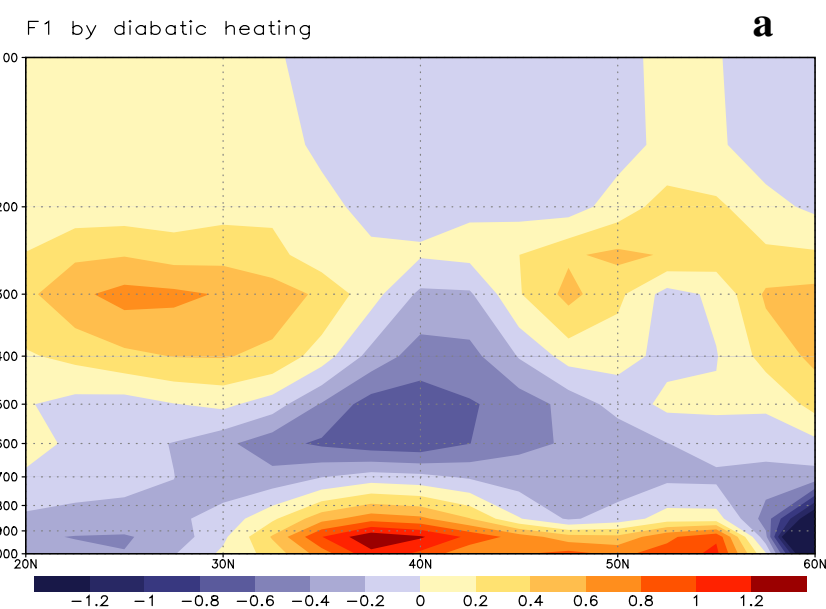

F2 by transient eddy heating
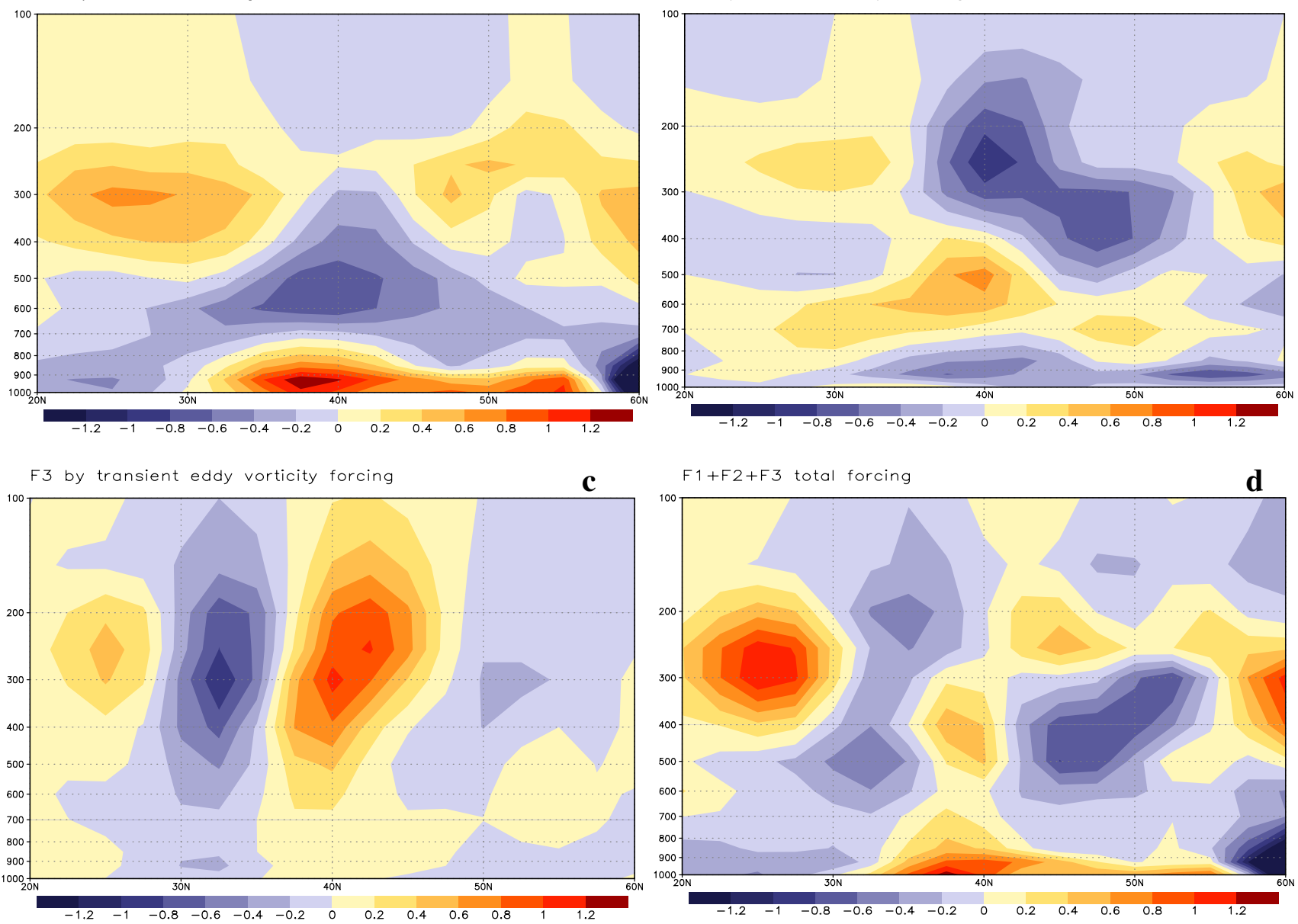

Fig. 12 Latitude-altitude sections of the regressed anomalies of PV sources $\left(10^{-11} \mathrm{~s}^{-2}\right)$ : a diabatic heat forcing F1, b transient eddy heat forcing $\mathrm{F} 2$, $\mathbf{c}$ transient eddy vorticity forcing F3, $\mathbf{d}$ total forcing $\mathrm{F} 1+\mathrm{F} 2+\mathrm{F} 3$, averaged between $150^{\circ} \mathrm{E}$ and $150^{\circ} \mathrm{W}$

substantially contributed from the transient eddy vorticity forcing (Fig. 12d).

By inverting the 3-D PV operator $\left(\nabla^{2}+\frac{f^{2}}{\sigma_{1}} \frac{\partial^{2}}{\partial p^{2}}\right)$ with Successive over-relaxation (SOR) method, we solve Eq. (4) numerically and obtain the initial geopotential tendency induced by different PV sources respectively (Fig. 13). The atmospheric geopotential response to $F_{1}$ and $F_{2}$ are also baroclinic, with a low in lower troposphere and a high in higher layers (Fig. 13a, b), similar to the results shown in Hoskins and Karoly (1981) and in Lau and Holopainen (1984). Furthermore, the atmospheric response to $F_{1}$ is relatively weak, and it almost offsets the response to $F_{2}$ below $400 \mathrm{hPa}$. Nevertheless, the barotropic transient eddy vorticity forcing anomaly can lead to an in-phase batrotropic geopotential response, which shows a barotropic geopotential low over the midlatitude North Pacific (Fig. 13c). The total geopotential tendency induced by the three forcing terms is also barotropic north of $35^{\circ} \mathrm{N}$. Over the midlatitude North Pacific, it shows a geopotential low that is determined by $F_{3}$, and over the high-latitude North Pacific, it shows a geopotential high that is contributed from both $F_{2}$ and $F_{3}$ (Fig. 13d). Therefore, compared to the baroclinic atmospheric response to the diabatic and transient eddy heating anomalies, the transient eddy vorticity forcing anomalies play a more important role in generating and maintaining typical equivalent barotropic anomalous atmospheric heights on decadal timescale in the midlatitude North Pacific.

\section{A mechanism for the unstable midlatitude ocean-atmosphere interaction}

Based on above analyses in Sects. 4 and 5, we can link the two parts together and propose a hypothesis on the mechanism for the unstable ocean-atmosphere interaction in the midlatitude North Pacific, as illustrated in Fig. 14.

Suppose that there is an initial midlatitude surface westerly wind anomaly companied with the intensified Aleutian 


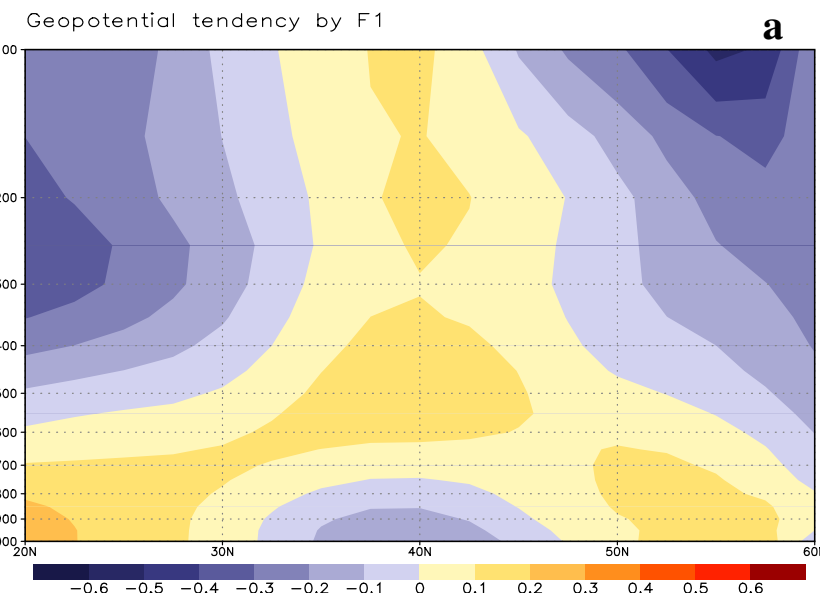

Geopotential tendency by F3

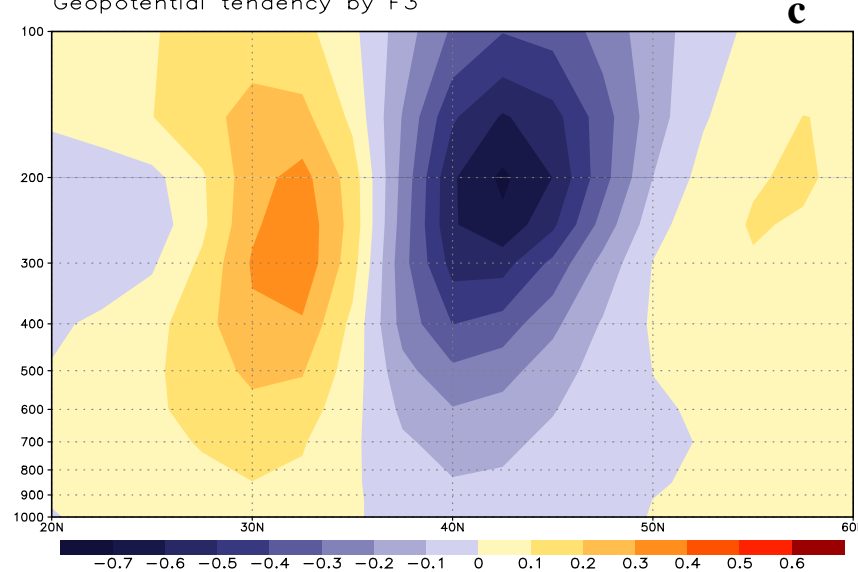

Geopotential tendency by F2

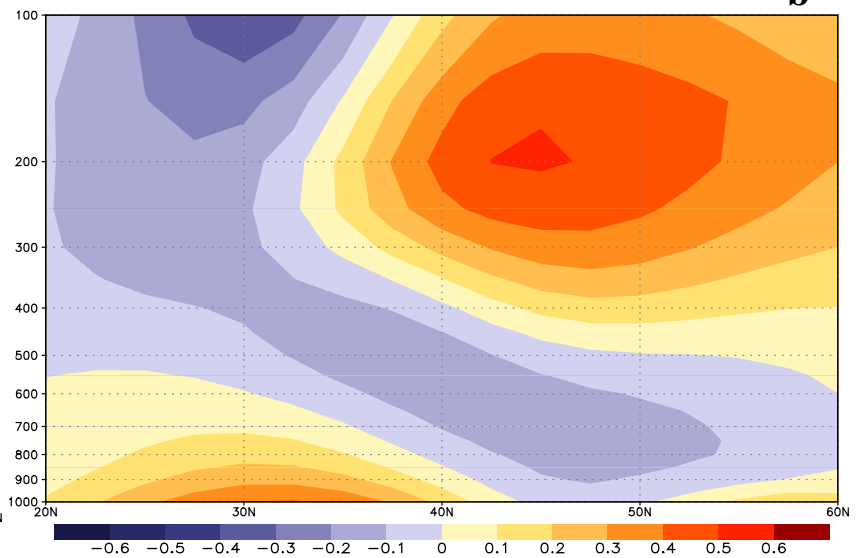

Geopotential tendency by $\mathrm{F} 1+\mathrm{F} 2+\mathrm{F} 3$

d

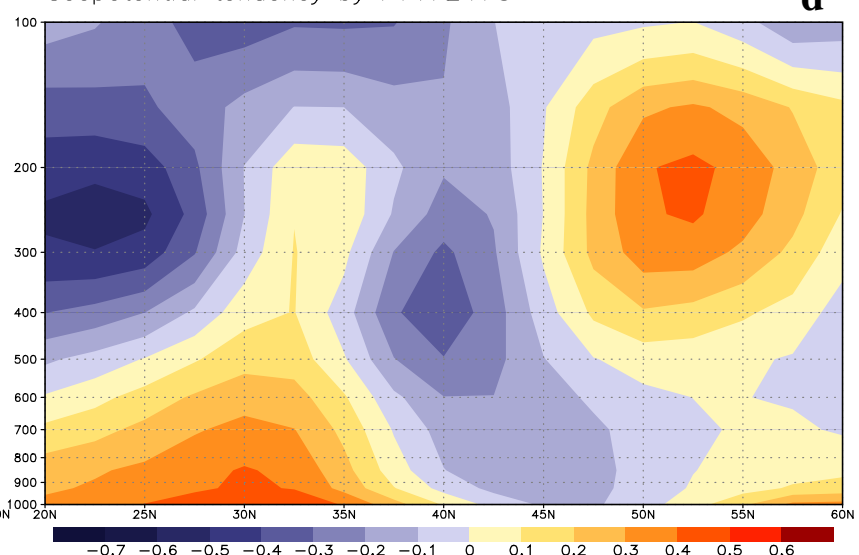

Fig. 13 Latitude-altitude sections of the geopotential tendencies $\left(10^{-3} \mathrm{~m}^{2} \mathrm{~s}^{-3}\right)$ induced by a diabatic heat forcing F1, b transient eddy heat forcing F2, c transient eddy vorticity forcing F3, d total forcing F1 $+\mathrm{F} 2+\mathrm{F} 3$, averaged between $150^{\circ} \mathrm{E}$ and $150^{\circ} \mathrm{W}$

Fig. 14 Schematic diagram for a positive ocean-atmosphere feedback in the midlatitude North Pacific

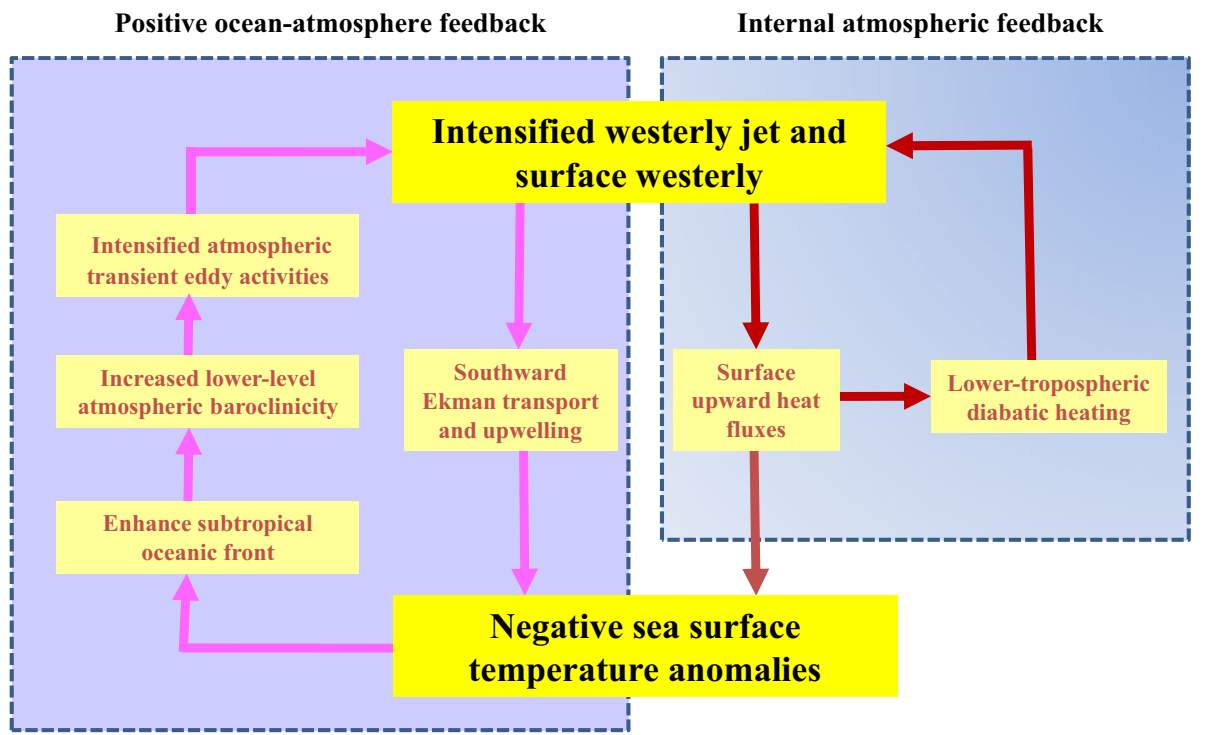


low. Then, the intensified surface westerly will lead to a basin-scale oceanic surface cooling (negative SST anomaly) by enhancing the upward surface (sensible and latent) heat fluxes and driving the southward Ekman transport and the upwelling north of the westerly anomaly. Due to the enhanced heat transfer from the ocean, the direct diabatic heating in the lower-level atmosphere will increase over the cold SST region. On the other hand, the negative SST anomaly will increase the meridional SST gradient and thus enhance the subtropical oceanic front. As an adjustment of the atmospheric boundary layer to the enhanced oceanic front (Sampe et al. 2010), the low-level atmospheric meridional gradient and thus the low-level atmospheric baroclinicity will be strengthened. Consequently, the atmospheric transient eddies in the zone with increasedbaroclinicity will become more active and induce more northward transport of heat and vorticity fluxes. Hence both the transient eddy heating and vorticity forcing increase in the central-to-eastern North Pacific. The response of the midlatitude atmospheric circulation to both the diabatic heating and the transient eddy heating tends to be baroclinic, whereas that to the transient eddy vorticity forcing is barotropic. However, the response to all of the three forcing sources tends to be a lower-level geopotential low north of the initial westerly anomaly, but the atmospheric response to the transient eddy vorticity forcing is dominant, which displays an equivalent barotropic geopotential low centered at the upper troposphere over the North Pacific. Therefore, the initial anomalies of the midlatitude westerly and Aleutian low will be further intensified, indicating an air-sea positive feedback in the midlatitude North Pacific.

It is worthwhile to further note that the midlatitude ocean that is entirely driven by the atmosphere is just passive in the feedback between the wind, the surface heat fluxes, and the diabatic heating (see the right part of Fig. 14). Such a feedback can be considered as an internal atmospheric feedback process. If only this feedback works, the atmospheric geopotential response will be baroclinic with low-level low and high-level high above the cold water. The related air temperature anomaly will be positive and barotropic according to static equilibrium equation $(\partial \Phi / \partial p=-R T / P)$. Then the low-level cold air temperature (Fig. $2 \mathrm{~g}$ ) will be cancelled and the upward surface heat flux will be reduced or even change its sign. Therefore, the internal feedback cannot sustain the initial anomalies. However, in the feedback between the wind, the sea surface temperature, the oceanic front, the atmospheric baroclinicity, and the atmospheric transient eddy forcing (the left part of Fig. 14), the ocean and the atmosphere are fully coupled, and the ocean can influence the atmosphere via indirect thermal and dynamical forcing of transient eddies, especially via the transient eddy dynamical (momentum or vorticity) forcing. Hence, the midlatitude ocean-atmosphere interaction can provide a positive feedback mechanism for the development of initial anomaly, in which the oceanic front and the atmospheric transient eddy are the indispensable ingredients. Such a positive feedback mechanism is fundamentally responsible for the observed decadal anomalies (Figs. 2, 3), as described in Sect. 3, with equivalent barotropic trough (ridge) over cold (warm) water (i.e., socalled cold/trough or warm/ridge pattern) in the midlatitude North Pacific ocean-atmosphere system.

\section{Conclusions and discussion}

Observational studies have revealed that there is a significant decadal variability in the midlatitude North Pacific ocean-atmosphere system, and that the decadal mode of North Pacific SST anomalies, which is called the Pacific Decadal Oscillation (PDO), is well correlated with the atmospheric anomalies, especially during boreal winter. A detailed analysis of the 3-D distribution and configuration relationship of decadal climate anomalies in the North Pacific has been conducted in this study, showing that corresponding to a basin scale SST cooling (warming) for a positive (negative) PDO phase, the atmospheric geopotential height aloft dispalys an equivalent barotropic low (high) anomaly throughout the troposphere. This equivalent barotropic cold/trough (warm/ridge) structure is the major feature of North Pacific climate variability on decadal timescale. Due to the long evolution time of upper-ocean, the midlatitude ocean-atmosphere interaction is widely considered to be the potential source of decadal climate variability. Yet there is still not a relative complete theoretical framework for the ocean-atmosphere interaction in the midlatitudes until now, mainly because that the impact of the midlatitude ocean on the atmosphere has not been fully understood. In this study, we have explored the processes of ocean-atmosphere interaction, especially how the atmosphere responds to the SST anomalies in the midlatitude North Pacific, based on observational diagnoses.

In the midlatitudes, the forcing from the atmosphere on the ocean is much more significant than the reverse. The cold SST anomaly in the North Pacific is generated mainly by the strengthened westerly through the enhanced upward heat flux, and also through the southward Ekman current in the upper ocean. Despite the major role of the atmosphere in the midlatitude air-sea system, the ocean's effect on the atmosphere can still be detected in the view of atmospheric forcing sources.

The midlatitude atmospheric circulation is generally thermal- and eddy-driven. On the seasonal timescale, the forcing sources include the diabatic heating, the transient eddy heating, and the transient eddy vorticity forcing. The latter two items that reflect the convergence of the heat and vorticity 
(or momentum) transport by transient eddies, respectively, can be considered as indirect forcing sources of atmospheric circulation. Through these forcing sources, the midlatitude ocean's thermal condition can affect the atmosphere.

Associated with the decadal SST cooling over the midlatitude North Pacific during a warm PDO phase, the decadal anomalies of diabatic heating, transient eddy heating and transient eddy vorticity forcing are all positive over the central-to-eastern North Pacific. The increased diabatic heating is mainly induced by the increased latent and sensible heat fluxes from the ocean, and it is much significant in the lower-to-middle troposphere. The increased transient eddy heating is due to the intensified subtropical SST front and lower-level atmospheric baroclinicity, and it is much significant in the higher troposphere. Thus, the maximum center of the total heating is at the upper troposphere, mostly contributed from the transient eddy heating, while in the lower troposphere it is dominated by the diabatic heating. The increased transient eddy vorticity forcing is much significant in the upper troposphere, with an equivalent barotropic structure, and it is in phase with the anomalous geopotential low.

Based on detailed quantitative analyses, we find that the effects of the diabatic heating, transient eddy heating and transient eddy vorticity forcing on the seasonal mean atmospheric circulation are quite different. The atmospheric response to either shallow diabatic heating or deep transient eddy heating is dynamically baroclinic, whereas the response to the transient eddy vorticity forcing is equivalent barotropic. The increased transient eddy vorticity forcing tends to produce an equivalent barotropic geopotential low over the cooling SST that is consistent with the observation.

Furthermore, we find that the transient eddy activities are closely related to the oceanic front zones, especially the subtropical SST front in the North Pacific. The decadal SST cooling over the midlatitude North Pacific during a warm PDO phase leads to an intensification of the SST front, giving rise to an increase of the lower-level atmospheric baroclinicity aloft. It is via the enhanced subtropical oceanic front that the cooling midlatitude SST anomalies can intensify the atmospheric transient eddy activities.

In terms of the analyses in this study, it is suggested that the midlatitude ocean-atmosphere interaction can provide a positive feedback mechanism for the development of initial anomaly, in which the oceanic front and the atmospheric transient eddy are the indispensable ingredients. A mechanism for the unstable ocean-atmosphere interaction in the midlatitude North Pacific is proposed as follows. Suppose these is an initial midlatitude surface westerly wind anomaly companied with an intensified Aleutian low. Then, the westerly anomaly will lead to a basin-scale SST cooling by enhancing the upward surface heat fluxes and driving the southward Ekman transport and the upwelling north of the westerly anomaly. The SST cooling tends to increase the meridional SST gradient, thus enhancing the subtropical oceanic front. As an adjustment of the atmospheric boundary layer to the enhanced oceanic front, the low-level atmospheric meridional gradient and thus the low-level atmospheric baroclinicity tends to be strengthened, inducing more active transient eddy activities that increase transient eddy vorticity forcing. Such a vorticity forcing tends to produce an equivalent barotropic geopotential low north of the initial westerly anomaly. Therefore, the initial anomalies of the midlatitude surface westerly and Aleutian low will be further intensified. Such a positive ocean-atmosphere feedback mechanism is very well responsible for the observed decadal anomalies with equivalent barotropic trough (ridge) over cold (warm) water (i.e., so-called cold/ trough or warm/ridge pattern) in the midlatitude North Pacific ocean-atmosphere system.

In the diagnostic analysis of this paper, the seasonal mean data is used to obtain the relationship among oceanic and atmospheric anomalies. This relationship can be understood among equilibrium states resulting from the interactions of these fields. The lead/lag relationship between the oceanic and atmospheric variables especially for the case in which the ocean leads the atmosphere needs to be further examined using shorter time interval (say, daily or weekly) data. Since the atmospheric response to SST anomalies is very fast, high-resolution satellite data for SST and atmospheric winds and more ingenious statistical methods should be used to further analyze the detailed feedback processes involving transient eddy activities, especially in SST frontal zones. Moreover, in the present paper, transient eddies refer to all the eddies on the timescale shorter than one season. The relative role of synoptic eddies and low-frequency (subseasonal) eddies in the midlatitude air-sea interaction also need to be further identified.

Acknowledgments This work is jointly supported by the National Natural Science Foundation of China under Grants 41375074, 41330420. The authors are grateful to Ms. Liying Wang and Ms. Shuang Qiu for their assistance in making the plots of this manuscript. The authors would also appreciate two anonymous reviewers for their constructive comments and suggestions to improve the manuscript.

Open Access This article is distributed under the terms of the Creative Commons Attribution 4.0 International License (http://creativecommons.org/licenses/by/4.0/), which permits unrestricted use, distribution, and reproduction in any medium, provided you give appropriate credit to the original author(s) and the source, provide a link to the Creative Commons license, and indicate if changes were made. 


\section{References}

Cayan DR (1992) Latent and sensible heat-flux anomalies over the northern oceans - the connection to monthly atmospheric circulation. J Clim 5:354-369

Chu CJ, Yang XQ, Ren XJ, Zhou TJ (2013) Response of Northern Hemisphere storm tracks to Indian-western Pacific Ocean warming in atmospheric general circulation models. Clim Dyn 40(5-6):1057-1070

Czaja A, Blunt N (2011) A new mechanism for ocean-atmosphere coupling in midlatitudes. Q J R Meteorol Soc 137:1095-1101

Davis RE (1976) Predictability of sea surface temperature and sea level pressure anomalies over the North Pacific Ocean. J Phys Oceanogr 6:249-266

Davis RE (1978) Predictability of sea level pressure anomalies over the North Pacific Ocean. J Phys Oceanogr 8:233-246

Deser C, Blackman M (1993) Surface climate variations over the North Atlantic Ocean during winter: 1900-1989. J Clim 6:1743-1753

Deser C, Magnusdottir G, Saravanan R, Phillips A (2004) The effects of North Atlantic sst and sea ice anomalies on the winter circulation in CCM3. Part II: direct and indirect components of the response. J Clim 17:877-889

Ebbesmeyer CC, Cayan DR, Milan DR, Nichols FH, Peterson DH, Redmond KT (1991) 1976 step in the Pacific climate: forty environmental changes between (1968-1975 and 1977-1984). In: Betancourt JL, Sharp VL (eds) Proceedings of the seventh annual Pacific Climate (PACLIM) Workshop, April (1990). California Department of Water Resources Interagency Ecological Studies Program Tech Rep 26, pp 129-141

Enfield DB, Mestas-Nunez AM (1999) Multiscale variabilities in global sea surface temperatures and their relationships with tropospheric climate patterns. J Clim 12:2719-2733

Fang JB, Yang XQ (2011) The relative roles of different physical processes in the unstable midlatitude ocean-atmosphere interactions. J Clim 24:1542-1558

Fang JB, Rong XY, Yang XQ (2006) Decadal-to-interdecadal response and adjustment of the North Pacific to prescribed surface forcing in an oceanic general circulation model. Acta Oceanol Sin 25(3):11-24

Feliks Y, Ghil M, Simonnet E (2004) Low-frequency variability in the midlatitude atmosphere induced by an oceanic thermal front. J Atmos Sci 61:961-981

Feliks Y, Ghil M, Simonnet E (2007) Low-frequency variability in the midlatitude baroclinic atmosphere induced by an oceanic thermal front. J Atmos Sci 64:97-116

Feliks Y, Ghil M, Robertson AW (2011) The Atmospheric circulation over the North Atlantic as induced by the SST field. J Clim 24:522-542

Francis RC, Hare SR (1997) Regime scale climate forcing of salmon populations in the Northeast Pacific-some new thoughts and findings. In: Emmett RL and Schiewe MH (eds) Estuarine and ocean survival of Northeastern Pacific Salmon: proceedings of the workshop. U.S. Dep. Commer., NOAA Tech. Memo. NMFSNWFSC-29, pp 113-128

Frankignoul C (1985) Sea surface temperature anomalies, planetary waves and air-sea feedback in the middle latitudes. Rev Geophys 23:357-390

Frankignoul C, Muller P, Zorita E (1997) A simple model of the decadal response of the ocean to stochastic wind forcing. J Phys Oceanogr 27:1533-1546

Gill AE (1980) Some simple solutions for the heat-induced tropical circulation. Q J R Meteorol Soc 106:447-662

Graham NE, Barnett TP, Wilde R, Ponater M, Schubert S (1994) On the roles of tropical and midlatitude SSTs in forcing interannual to interdecadal variability in the winter Northern Hemisphere circulation. J Clim 7:1416-1441

Gu D, Philander SGH (1997) Interdecadal climate fluctuations that depend on exchange between the tropics and extratropics. Science 275:805-807

Hasselmann K (1976) Stochastic climate models. Part I: Theory. Tellus 28:473-485

Holopainen E, Rontu L, Lau NC (1982) The effect of large-scale transient eddies on the time-mean flow in the atmosphere. J Atmos Sci 39(9):1972-1984

Hoskins BJ, Karoly D (1981) The steady linear response of a spherical atmosphere to thermal and orographic forcing. J Atmos Sci 38:1179-1196

Kushnir Y (1994) Interdecadal variations in North Atlantic sea surface temperature and associated atmospheric conditions. J Clim $7: 141-157$

Kushnir Y, Held IM (1996) Equilibrium atmospheric response to North Atlantic SST anomalies. J Clim 9:1208-1220

Kushnir Y, Lau NC (1992) The general circulation model response to a North Pacific SST anomaly: dependence on timescale and pattern polarity. J Clim 5:271-283

Kushnir Y, Robinson WA, Bladé I, Hall NM, Peng S, Sutton R (2002) Atmospheric GCM response to extratropical SST anomalies: synthesis and evaluation. J Clim 15:2233-2256

Latif M, Barnett TP (1994) Causes of decadal climate variability over the North Pacific and North America. Science 266:634-637

Latif M, Barnett TP (1996) Decadal climate variability over the north pacific and North America: dynamics and predictability. J Clim 9:2407-2423

Lau NC, Holopainen E (1984) Transient eddy forcing of the timemean flow as identified by geopotential tendencies. J Atmos Sci 41:313-328

Liu Z (2012) Dynamics of interdecadal climate variability: a historical perspective. J Clim 25:1963-1995

Liu Z, Wu L (2004) Atmospheric response to North Pacific SST anomaly: the role of ocean-atmosphere coupling. J Clim 17:1859-1892

Liu CJ, Ren XJ, Yang XQ (2014) Mean flow-storm track relationship and Rossby wave breaking in two types of El-Niño. Adv Atmos Sci 31(1):197-210

Mantua NJ, Hare SR, Zhang Y, Wallace JM, Francis RC (1997) A Pacific interdecadal climate oscillation with impacts on salmon production. Bull Am Meteorol Soc 78:1069-1079

Matsuno T (1966) Quasi-geostrophic motion in the equatorial area. J Meteorol Soc Jpn 44:25-42

Miller AJ, Schneider N (2000) Interdecadal climate regime dynamics in the North Pacific Ocean: theories, observations and ecosystem impacts. Prog Oceanogr 47:355-379

Miller AJ, Cayan DR, Barnett TP, Graham NE, Oberhuber JM (1994) The 1976-1977 climate shift of the Pacific Ocean. Oceanography 7:21-26

Minobe S (1997) A 50-70 year climatic oscillation over the North Pacific and North America. Geophys Res Lett 24:683-686

Minobe S, Kuwano-Yoshida A, Komori N, Xie SP, Small RJ (2008) Influence of the Gulf Stream on the troposphere. Nature 452:206-209

Nakamura H, Sampe T, Tanimoto Y, Shimpo A (2004) Observed associations among storm tracks, jet streams and midlatitude oceanic fronts. Earth's climate: the ocean-atmosphere interaction. Geophys. Monogr., vol 147. American Geophysical Union, pp 329-345

Namias J, Cayan DR (1981) Large-scale air-sea interactions and short period climate fluctuations. Science 214:869-876

Neelin JD, Weng WJ (1999) Analytical prototypes for ocean-atmosphere interaction at midlatitudes. Part I: coupled feedbacks as 
a sea surface temperature dependent stochastic process. J Clim 12:697-721

Nie Y, Zhang Y, Yang XQ, Chen G (2013) Baroclinic anomalies associated with the Southern Hemisphere annular mode: roles of synoptic and low-frequency eddies. Geophys Res Lett 40:2361-2366

Nie Y, Zhang Y, Chen G, Yang XQ, Alex Burrows D (2014) Quantifying barotropic and baroclinic eddy feedbacks in the persistence of the Southern Annular Mode. Geophys Res Lett 41:8636-8644

Nitta T, Yamada S (1989) Recent warming of tropical sea surface temperature and is relationship to the Northern Hemisphere circulation. J Meteorol Soc Jpn 67:375-383

Palmer TN, Sun Z (1985) A modelling and observational study of the relationship between sea surface temperature in the northwest Atlantic and the atmospheric general circulation. Q J R Meteorol Soc 111:947-975

Peng S, Whitaker JS (1999) Mechanism determining the atmospheric response to midlatitude SST anomalies. J Clim 12:1393-1408

Peng S, Mysak A, Ritchie H, Derome J, Dugas B (1995) The difference between early and middle winter atmospheric response to sea surface temperature anomalies in the northwest Atlantic. J Clim 8:137-157

Peng S, Robinson WA, Hoerling MP (1997) The modeled atmospheric response to midlatitude SST anomalies and its dependence on background circulation states. J Clim 10:971-987

Picther EJ, Blackmon ML, Bates GT, Muñoz S (1988) The effect of North Pacific sea surface temperature anomalies on the January climate of a general circulation model. J Atmos Sci 45:172-188

Qiu B, Schneider N, Chen S (2007) Coupled decadal variability in the North Pacific: an observationally constrained idealized model. J Clim 20:3602-3620

Ren XJ, Yang XQ, Han B et al (2007) Storm track variations in the North Pacific in winter season and the coupled pattern with the midlatitude atmosphere-ocean system. Chin J Geophys 50(1):90-100

Ren XJ, Yang XQ, Chu CJ (2010) Seasonal variations of the synopticscale transient eddy activity and polar-front jet over east Asia. J Clim 23(12):3222-3233

Ren XJ, Yang XQ, Zhou TJ, Fang JB (2011) Diagnostic comparison of wintertime East Asian subtropical jet and polar-front jet: large-scale characteristics and transient eddy activities. Acta Meteorol Sin 25(1):21-33

Sampe T, Nakamura H, Goto A, Ohfuchi W (2010) Significance of a midlatitude SST frontal zone in the formation of a storm track and an eddy-driven westerly jet. J Clim 23:1973-6128

Saravanan R, McWilliams JC (1997) Stochasticity and spatial resonance in interdecadal climate fluctuations. J Clim 10:2299-2320

Saravanan R, McWilliams JC (1998) Advective ocean-atmosphere interaction: an analytical stochastic model with implications for decadal variability. J Clim 11:165-188

Small RJ, deSzoeke SP, Xie SP, O'Neill L, Seo H, Song Q, Cornillon P, Spall M, Minobe S (2008) Air-sea interaction over ocean fronts and eddies. Dyn Atmos Oceans 45:274-319
Taguchi B, Nakamura H, Nonaka M, Xie SP (2009) Influences of the Kuroshio/Oyashio extensions on air-sea heat exchanges and storm-track activity as revealed in regional atmospheric model simulations for the 2003/04 cold season. J Clim 22:6536-6560

Trenberth KE (1990) Recent observed interdecadal climate changes in the Northern Hemisphere. Bull Am Meteorol Soc 71:988-993

Wallace JM, Jiang QR (1987) On the observed structure of interannual variability of the atmosphere/ocean climate system. In: Cattle $\mathrm{H}$ (ed) Atmospheric and oceanic variability. Royal Meteorological Society, Reading, pp 17-43

Weng WJ, Neelin JD (1998) On the role of ocean-atmosphere interaction in midlatitude decadal variability. Geophys Res Lett 25:167-170

Xiang Y, Yang XQ (2012) The effect of transient eddy on interannual meridional displacement of summer east Asian subtropical jet. Adv Atmos Sci 29(3):484-492

Xu GY, Yang XQ, Sun XG (2005) Interdecadal and interannual variation characteristics of rain fall in North China and its relation with the northern hemisphere atmospheric circulations. Chin J Geophys 48(3):511-518

Yanai M, Tomita T (1998) Seasonal and interannual variability of atmospheric heat sources and moisture sinks as determined from NCEP-NCAR reanalysis. J Clim 11:463-482

Yang XQ, Zhu YM (2008) Interdecadal climate variability in China associated with the Pacific Decadal Oscillation. In: $\mathrm{Fu} \mathrm{C}$ et al (eds) Regional climate studies of China. Springer, Berlin, pp 97-118

Yang XQ, Xie Q, Zhu YM, Sun XG, Guo YJ (2005) Decadal-to-interdecadal variability of precipitation in North China and associated atmospheric and oceanic anomaly patterns. Chin J Geophys 48(4):789-797

Zhang Y, Yang XQ, Nie Y, Chen G (2012) Annular-mode-like variation in a multi-layer QG model. J Atmos Sci 69(10):2940-2958

Zhong YF, Liu Z, Jacob R (2008) Origin of Pacific multi-decadal variability in Community Climate System Model version (CCSM3): a combined statistical and dynamical assessment. J Clim 21:114-133

Zhu YM, Yang XQ (2003a) Joint propagating patterns of SST and SLP anomalies in the North Pacific on bidecadal and pentadecadal timescales. Adv Atmos Sci 20(5):694-710

Zhu YM, Yang XQ (2003b) Relationships between Pacific Decadal Oscillation (PDO) and climate variabilities in China. Acta Meteorol Sin 61:641-654 (in Chinese)

Zhu YM, Yang XQ, Xie Q, Yu YQ (2008a) Covarying modes of the Pacific SST and northern hemispheric midlatitude atmospheric circulation anomalies during winter. Prog Nat Sci 18:1261-1270

Zhu YM, Yang XQ, Xie Q, Yu YQ et al (2008b) Decadal variability in the North Pacific as simulated by FGOALS-g fast coupled climate model. Chin J Geophys 51(1):58-69 